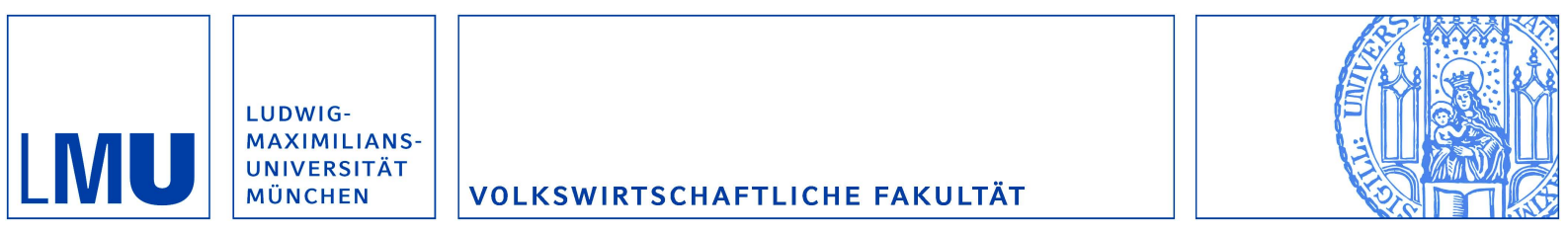

Kocher, Martin G.; Tan, Fangfang und Yu, Jing:

Providing global public goods: Electoral delegation and cooperation

Munich Discussion Paper No. 2014-36

Department of Economics

University of Munich

Volkswirtschaftliche Fakultät

Ludwig-Maximilians-Universitä† München

Online at https://doi.org/10.5282/ubm/epub.21163 


\title{
Providing global public goods: Electoral delegation and cooperation*
}

\author{
Martin G. Kocher ${ }^{\#}$, Fangfang Tan ${ }^{\S}$, and Jing $\mathrm{Yu}^{+}$
}

\begin{abstract}
This paper experimentally examines the effect of electoral delegation on providing global public goods shared by several groups. Each group elects a delegate who can freely decide on each group member's contribution (including the contribution of herself) to the global public good. Our results show that people mostly vote for delegates who assign equal contributions for every group member. However, in contrast to standard theoretical predictions, unequal contributions across groups drive cooperation down over time, and it decreases efficiency by almost $50 \%$ compared to the benchmark. This pattern is not driven by delegates trying to exploit their fellow group members, as indicated by the theory - quite to the opposite, other-regarding preferences and a re-election incentives guarantee that delegates assign equal contributions for all group members. Since the source of the resulting inefficiency is the polycentric nature of global public goods provision together with other-regarding preferences, we use the term $P$ inefficiency to describe our finding.
\end{abstract}

This version: July $24^{\text {th }}, 2014$

JEL Code: C92, D72, H41

Keywords: Global Public Goods, Delegation, Cooperation, Experiment

\footnotetext{
${ }^{*}$ We thank Daniel Houser, Jens Grosser, Ernesto Reuben, Roberto Weber, Johanthan Woon, participants of the ESA European Conference in Cologne, the ESA North American Meeting in Tucson, the first joint workshop between the University of Innsbruck and the Max Planck Institute for Tax Law and Public Finance, the 88th Western Economic Association International (WEAI) Annual Conference in Seattle, as well as seminar participants at the Universities of Amsterdam, Munich, Vermont, and Zurich for helpful comments and suggestions. All remaining errors are ours.

\# University of Munich, Queensland University of Technology, and University of Gothenburg. Address: Department of Economics, University of Munich, Geschwister-Scholl-Platz 1, 80539 Munich, Germany. E-mail: martin.kocher@1rz.unimuenchen.de.

${ }^{\S}$ Corresponding author. Max-Planck Institute for Tax Law and Public Finance. Address: Marstallplatz 1, Munich, Germany. Email: fangfang.tan@tax.mpg.de.

${ }^{+}$University of Munich. Address: Department of Economics, University of Munich, Geschwister-Scholl-Platz 1, 80539 Munich, Germany. E-mail:Jing.Yu@campus.lmu.de.
} 


\section{Introduction}

Maintaining an efficient provision of public goods on the international or global level is a difficult task. Despite the large number of examples of global public goods - e.g., climate protection, biodiversity, international security, and scientific knowledge - economic research on the efficient management of these goods is still in its infancy. In general, global public goods are vital to human welfare, yet often underprovided or common goods are over-exploited because of their non-excludable benefits spilling over country borders. For instance, about $90 \%$ of marine fish stocks in the oceans have been over-exploited, fully exploited, or have completely collapsed by 2009 (Froese et al., 2012).

The management of global public goods is usually organized on multiple, hierarchical scales. This means that global public goods are often governed through a delegated institution whose officials (representatives) are elected or appointed by national (or regional) provision collectives. Is electoral delegation an effective mechanism in sustaining efficient provision levels of a global public good? Despite its obvious relevance, an empirical assessment of the effectiveness of delegation mechanisms of global public goods provision in the field is difficult due to lack of controlled data. Recently, a burgeoning literature has started to use laboratory experiments to address this research question (see Hamman et al., 2011, and Bernard et al., 2013). ${ }^{1}$

The straightforward advantage of a provision collective consisting of delegates is that delegates can make efficient use of the resources by taking centralized decisions that help coordination within and across societies. Nevertheless, the absence of global authority means that there is a temptation to free ride and that global public goods are likely to be under-provided or not provided at all (e.g., Conceicao, 2003; Barrett, 2007; Aronsson and Johansson-Stenman, 2014; Löschel and Rübbelke, 2014). Another possible cause for the failure is widely discussed in interest-group theory: Political decision makers in power favor the organized "few" at the expense of the unorganized "many" (McCormick and Tollison, 1981). These considerations create an interesting dilemma for voters in the selection of their representatives. Is it better to delegate a pro-social representative who strives for cooperation when interacting with other representatives, but runs the risk of being exploited by other groups or their representatives? Or, is it better to choose an egoistic representative who increases own-group profit by free-riding on other groups' contributions, but might be inclined to abusing her power at hand by exploiting her fellow group members?

\footnotetext{
${ }^{1}$ Surveys of public goods experiments that do not implement delegation are provided in Ledyard (1995) and Chaudhuri (2011). By design our setup is related to a small body of literature on public goods provision that involves multiple layers of independent contribution decisions (see, e.g., Blackwell and McKee, 2003; Fellner and Lünser, 2014). A key feature that differentiates our study from theirs is that decision makers in multi-level public goods games need to trade off contributions between a local and a global level public good. Our setting, however, focuses on the provision of global level public goods.
} 
In this paper, we focus on a key determinant of electoral delegation ${ }^{2}$ in the provision of global public goods: the interactions between voters and political representatives/delegates. To do so, we devise a laboratory experiment that abstracts from some of the complexity in real-world global public goods provision, but highlights the polycentric nature. This concept, first discussed in Ostrom et al. (1961), describes the complexity of global public goods provision as involving "many centers of decision making that are formally independent of each other" (for a more detailed discussion, see Ostrom, 2010).

In our two-level provision mechanism, the delegate is able to determine the provision vector of all members of her provision group on the lower level (the group level), and she interacts with other delegates on the super-group or society level when providing a global public good. Think of her as a national minister or a head of state in the European Union (EU) who makes decisions on global public goods contributions (e.g., the national contribution to European battle groups) on behalf of the voters in the country she represents. Notice that the group contribution decision in the real world can also be implicit through a national decision on the distribution of the tax burden or through a decision on the design of the redistributive system of a jurisdiction. The decisions of all representatives of all EU countries determine the total contributions at the EU level. ${ }^{3}$ An egoistic representative might be an asset in the interaction on the super-group level because she is not taken advantage of by other representatives, but she might exploit part of her own citizens (the own group members) when financing the contributions to the public good by letting them contribute over-proportionately (and/or free riding on them). In contrast, a cooperative representative might use a fair proportional contribution rule within her group that does not exploit anybody, but her group could be exploited on the society level by the potentially egoistic representatives of other groups.

To sum up, our setup is able to address empirically (i) the overall effect of electoral delegation on the efficiency of global public goods provision; (ii) to what extent and how precisely delegation might be able to overcome the lack of global authority and to coordinate the provision of global public goods; and (iii) the potential of an election procedure to (partly) curb the abuse of power by representatives. A laboratory experiment allows us to isolate the incentive effects and should be viewed as a platform for studying cooperation and delegation that is complementary to field studies. It enables us to assess cooperative preferences and their impact on elections and public goods provision by delegates on the micro-level. ${ }^{4}$

\footnotetext{
${ }^{2}$ Delegation in principal-agent settings has attracted considerable attention in the experimental economics literature recently (see, for instance, Bartling and Fischbacher, 2012).

${ }^{3}$ Likewise, in mitigating global warming, decisions of all representatives of countries determine the total reduction of $\mathrm{CO}_{2}$ emission via multilateral agreements such as the Kyoto protocol.

${ }^{4}$ Needless to say, having field data on the important aspects in our setup would be desirable. However, some of the variables are, by their very nature, difficult to observe in the field or strongly confounded.
} 
More precisely, in our experiment, nine decision makers form a society, and they are divided into three groups of population size three each. In the Baseline treatment, players in each group have to make simultaneous and independent decisions about how much to contribute to a global public good provided on the level of the nine-person society. The total contributions from all members of the three groups are multiplied and are then equally distributed among all players in the groups. The parameters are chosen in a way to induce a linear social dilemma that maximizes the distance between the individually optimal and the socially optimal choices of the group members. In the Delegation treatment, we introduce a Borda count as the election rule for the delegation mechanism. The candidate with the smallest total sum of ranks in each group becomes the delegate for her group for the upcoming three periods of interaction. In the contribution stages of the public goods game in each period, only the three delegates make decisions for each of their three group members. More specifically, they submit a contribution vector for the three members of their groups (including themselves). This vector can induce equal or unequal contributions within a group. Other group members than the delegates remain passive observers of the provision decisions. This design feature captures the fact that delegates are able to maximize their personal gain at the expense of the majority of voters. It can, for instance, be viewed as the potential for corrupt officeholding by the delegate or as "pork barrel" politics, but within the logic of the public goods game, it is simply free riding on the benefits of the public good without contributing oneself. In reality, there are of course limits to such kinds of behavior, but in order to have a clear incentive structure and the most straightforward experimental design, we maximize the potential for free riding by the delegate in our experiment.

Since our baseline is a standard finitely repeated linear public goods game, the unique subgame perfect equilibrium is zero contributions for all players. In the Delegation treatment, a profit-maximizing delegate would fully exploit the other two members of her group, because she benefits from the contributions of the other group members. More specifically, she would force the two other group members to contribute fully and thus entirely free-ride on them. Therefore, by construction, compared to Baseline, efficiency (i.e., the total earnings of all players) in the Delegation treatment increases in equilibrium. Models taking inequity-averse preferences into account (e.g., Fehr and Schmidt, 1999) give slightly different predictions, but exploitation is still likely to take place in the stage game.

Our experiment results of Baseline are by and large in line with theoretical predictions based on standard preferences. Without delegation, cooperation quickly declines to low levels in the finitely repeated game. Compared to Baseline, both contributions and earnings are higher in Delegation. In contrast to standard predictions, the elected delegates avoid exploiting other group members by assigning equal contributions to the three group members, driven either by genuine other-regarding preferences or an opportunistic re-election (reputation) motive. However, despite the existence of other-regarding 
preferences, we observe that the actual contribution levels in our experiment are significantly below the theoretical benchmark with self-regarding preferences, and they steadily decline over time. ${ }^{5}$ In effect, delegates who over-contribute compared to other delegates in the society are less likely to be re-elected. As a consequence, a downward spiral of contribution levels for the global public good sets in. The combination of (i) delegation based on (re)-election and (ii) heterogeneity in other-regarding preferences leads to an inefficiency for which we use the term P-inefficiency, associating with a global public good's polycentric nature. Both ingredients, the re-election concern and heterogeneity across different groups in terms of other-regarding preferences, are obviously necessary for existence of the P-inefficiency. However, any of the two elements seems natural in the provision and management of global public goods.

In spite of the enormous amount of evidence on the private provision of public goods based on laboratory experiments and a growing number of papers on delegation in principal-agent settings, the literature closely related to our setup is very small. Hamman et al. (2011) study the effect of electoral delegation in a linear public goods game. In their delegation treatments, nine players in a group have to choose a single allocator who decides about the amount of contributions for everyone in the group. Although they find that a couple of minimum winning coalitions in the election game for allocation power reap the benefits of the public good at the cost of other players in the group, most groups in their experiment elect high contributors who implement full contribution levels for all group members including themselves. Bolle and Vogel (2011) examine a similar setting and report that both elected and randomly appointed allocators increase the levels of public goods provision over the benchmark of the standard linear public goods game, although the effect becomes smaller with repetition. In addition, Oxoby (2006) and Fleiß and Palan (2012) also find that contributions increase when a randomly selected delegate can choose contribution levels for all group members. ${ }^{6}$

The difference between our study and those discussed in the previous paragraph lies in the particular group and society structure naturally caused by global public goods provision. In the existing studies, the delegates act like dictators since they can determine the level of contributions for every person in society without any restrictions. In other words, the public goods provision contains no hierarchical structure. In our setting, however, the decision power of the delegate is confined to her own group. The total level of

\footnotetext{
${ }^{5}$ Note that efficiency is maximized when all delegates contribute for every group member (including themselves) the entire endowment to the public good. The full exploitation solution according to which the three delegates free ride and make the two other members within their respective groups provide full contributions gives another benchmark for the achievable level of efficiency.

${ }^{6}$ There is a growing body of literature that studies the effects of delegating punishment or implicit punishment to a centralized authority and the willingness of groups to do so (see, e.g., Kosfeld et al., 2009; Baldassarri and Grossman, 2011; Andreoni and Gee, 2012; Tan and Xiao, 2012; Markussen et al., 2014).
} 
public goods provision is determined by the simultaneous and independent decisions of the three delegates on behalf of their groups. Hence, not only do they face a redistribution problem within their groups, but they also have to deal with the strategic interactions with other delegates across groups.

The only study that introduces both the subgroup and the delegation elements, to the best of our knowledge, is Bernard et al. (2013). They compare several voting schemes in extracting common pool resources, which share a similar payoff structure as the public goods game. In one of these mechanisms, a randomly chosen player in every period votes, on behalf of her group, on the level of extractions for the entire group. They find that this mechanism is effective in overcoming the tragedy of the commons, since the decisions of the delegate affect the group as a whole. In their setting, the median of all extraction proposals made by the delegates was implemented automatically, making it easier to prevent a group from implementing an extreme extraction level by construction. In the other mechanism, each player votes for the level of extractions implemented at their own group level in each period. They find that the extraction level is not only higher but it also increases over time with this mechanism due to defection by other groups that extract from the common pool. Compared to their paper, our study allows the delegates to choose contribution strategies for each member of their own groups without any restrictions throughout their tenures. Moreover, our paper focuses on elected delegates instead of randomly assigned delegates. Data from the elections help us uncover the motives and expectations of players and enable us to assess the preferences of group members with regard to the characteristics of their representatives.

The remainder of the paper is organized as follows. Section 2 presents our experimental design. Section 3 derives theoretical predictions based on both self-interested and inequity-averse preferences. In Section 4, we present our empirical results, and Section 5 concludes the paper.

\section{Experimental design and procedures}

We implement two treatments in our study: Baseline (no delegation) as our control treatment and Delegation. Every experimental session with 18 experimental participants divides the participants into two cohorts (matching groups) of nine subjects each at the beginning of the experiment. Possible rematching takes place only within a cohort in order to guarantee strict statistical independence on the level of the super-group (society) of nine subjects. A total of seven experimental sessions provide us with six independent observations for Baseline and eight independent observations for Delegation. At the beginning of a session, subjects are informed that the experiment will consist of four parts. They receive instructions (see Appendix $\mathrm{C}$ for details) for the four parts separately, always before the start of a specific 
part. The first three parts of the experiment are identical across treatments; the treatment variation was introduced only in the fourth part.

The basic game that we use is a standard linear public goods game, presented in a neutral (i.e., context-free) frame to the participants. At the beginning of Part 1 subjects are randomly matched within their cohort into groups of three. Each of the three group members receives an endowment of 20 experiment points ${ }^{7}$, and they simultaneously have to decide about their individual contribution $\left(c_{i}\right)$ to a public account. The marginal per-capita return (MPCR) is set at 0.5 . The payoff function $\left(\pi_{\mathrm{i}}\right)$ for subject $i$ is

$$
\pi_{i}=20-c_{i}+0.5 \times \sum_{j=1}^{3} c_{j}
$$

with $c_{j}$ as the contribution of the $j$ members of the group.

More specifically, Part 1, aiming to measure cooperative preferences on the individual level, is a one-shot public goods game based on the strategy vector method developed by Fischbacher et al. (2001) and validated for repeated interactions by Fischbacher and Gächter (2010). Subjects are asked to make an unconditional contribution to the public good (an integer ranging from 0 to 20). Then, they need to specify their conditional contribution levels. In particular, they have to fill in a contribution table that indicates how much they want to put into the public account for each of the 21 possible average contributions of the other two group members (rounded up to the next integer). To ensure incentive compatibility, the computer randomly selects one subject within each group in the end and makes her conditional contribution table payoff-relevant. The two unconditional contributions from the remaining group members and the corresponding conditional contribution of the chosen subject are added up, and together they constitute the group's contribution to the public account.

Control questions, examples, screenshots and the possibility to ask questions before the start of Part 1 make sure that participants fully understand their available strategies and the nature of the interaction. We do not provide the subjects with any feedback on others' choices and earnings from Part 1 until the end of the four parts of the entire experiment to avoid contamination across parts. All details mentioned so far (except for the existence of two cohorts in one session) are common knowledge among participants.

At the beginning of Part 2, experimental participants are randomly re-matched into groups of three within their cohorts. Part 2 is a one-shot three-person allocation game (for instructions, see Appendix C). It uses exactly the same payoff function as in the previous part (see equation (1)), and it aims to provide a measure of distributive or other-regarding preferences on the individual level that is independent of any reputational concerns. Each group member decides on her own contribution to the public good as well as

\footnotetext{
${ }^{7}$ See Tavoni et al. (2011) for an interesting experiment with unequal endowments within a threshold public good environment.
} 
on the contributions of the other two group members. The program randomly selects one member from each group ex post and implements her allocation decision, i.e. the allocation choice of one of the three group members is implemented for the entire group with equal probability. Similar to the first part, no feedback on the results from Part 2 is provided until the very end of the experiment. All procedures are common knowledge.

In Part 3, subjects interact with each other for eight identical periods in a standard linear public goods game based on the payoff function in equation (1). At the beginning of the third part, random matching within the cohort into groups of three takes place, and groups now stay together for the entire eight periods of Part 3 (for the experimental instructions, please see Appendix C). After each period, subjects receive feedback on the contributions and earnings of all members of their group. Part 3 provides our participants with enough experience on the repeated voluntary contribution mechanism for the following Part 4 that is by its nature more complicated due to the delegation procedure in Delegation. Each period and every decision is payoff-relevant in Part 3.

After conclusion of Part 3, subjects receive instructions for Part 4 (see Appendix C). Part 4 is different in the two treatments. In both treatments, however, subjects are told that the composition of their group and their experimental IDs remain unchanged from the ones in Part 3. They are, further, informed that their group and two other groups (from the same matching cohort) will be matched into a super-group of nine members for the next (and final) 18 periods of interaction.

In Baseline, every member in the three groups simultaneously decides on how much to contribute to the super-group account. The super-group account collects the sum of all contributions from the nine super-group members. Define $c_{i K}$ as the contribution of member $i$ in group $K$. The payoff function $\left(\pi_{i K}\right)$ for subject $i$ in group $K$ becomes

$$
\pi_{\mathrm{iK}}=20-\mathrm{c}_{\mathrm{iK}}+\frac{1.5}{9} \sum_{\mathrm{K}=1}^{3} \sum_{\mathrm{j}=1}^{3} \mathrm{c}_{\mathrm{jK}}
$$

The sum of contributions by all nine super-group members (denoted by $C$ in the following) is multiplied by the social marginal benefit 1.5 and then equally distributed across the three groups. Within each group, the amount is also divided equally, and, hence, each member receives $(0.5 \times C) / 3$. Therefore, monetary incentives are the same as in Parts 1-3. Moreover, the standard game-theoretic equilibrium and the social optimal choices remain unchanged (see Section 3 for details).

In Delegation, we use exactly the same payoff function. However, groups need to elect a delegate who makes a binding decision for the contributions of each member, i.e. she submits a contribution vector consisting of three elements, one for each of the three group members including the contribution of herself. Delegates are elected for a three-period tenure. New elections take place after these three periods. 
The delegate is elected via a simple Borda count. That is, every member of a group is a voter and ranks the candidates (including herself) in order of individual preferences (with 1 as the most preferable rank). The computer, then, sums up the ranks of the three candidates within a group and appoints the candidate with the lowest rank sum as the delegate. In case of ties, one of the tied candidates is randomly selected as delegate for her group. When casting their vote, subjects can see the average contributions of the three members within their groups from Part 3 of the experiment as well as the following pieces of information from Part 4 (starting from period 4 in Part 4 onwards): (i) the ID of the delegate of their group in the previous three periods; (ii) the vectors of contributions and earnings of all members in one's own group for the previous three periods; (iii) the average contributions of the two other groups within the supergroup in each of the previous three periods. It is important to note that our design implies that members from the other two groups can neither influence the contribution decisions nor the election/replacement of a delegate outside their groups.

After the election, everyone within a group is informed about the IDs of the three delegates who make contribution choices on behalf of their group members for the next three periods. At the end of each single period in Part 4, everyone within a group receives information regarding the delegate ID, the contributions and earnings of each member in her own group, and the total contributions of each of the three groups. To facilitate comparisons, we present subjects in Baseline with exactly the same information without any reference to delegation or elections.

The experiment was conducted in the MELESSA laboratory at the University of Munich from February to April 2012. A total number of 126 student subjects with various academic backgrounds were recruited via ORSEE (Greiner, 2004). Subjects remained anonymous throughout the experiment, and cash payments were made privately. The experiment was programmed and conducted with the software z-Tree (Fischbacher, 2007). An experimental session lasted for a bit less than two hours, on average. Subjects earned an average of $€ 22.05$ (including a $€ 4$ show-up fee).

\section{Theoretical expectations}

In this section, we derive equilibrium predictions for our experiment. We start with standard preferences and extend our analysis to inequity-averse preferences. Our focus is on Parts 3 and 4. Predictions for the earlier parts in our experiment follow immediately from the discussion regarding Parts 3 and 4.

\subsection{Predictions based on selfish preferences}


The predictions for Baseline and the eight-period public goods game in Part 3 are straightforward. With rational, selfish, and risk-neutral group members and common knowledge thereof, the unique sub-game perfect equilibrium in the finitely-repeated game is to contribute zero to the linear public good. The marginal per capita return of the public good is always lower than the marginal return of keeping one's endowment in the linear public goods game that we use. The social optimum, however, is to contribute the entire endowment to the public account, since the social return is larger than one.

Hypothesis 1(a) for Baseline: Players will contribute zero to the global public good.

We now turn to Delegation. Under the homo oeconomicus assumption, the unique sub-game perfect equilibrium collapses to the following stage game equilibrium of the finitely repeated game: The delegate fully maximizes her monetary payoff by contributing zero and forcing the other two group members to contribute their entire endowment to the public good. Doing so maximizes the delegate's monetary earnings because she can free ride on the contributions of the other two group members.

Hypothesis 1(b) for Delegation: The elected delegate will assign full contributions for the other two group members and zero contribution for herself.

Let us now consider the voting stage that takes place every three periods in Delegation. Since the delegate has the potential to earn more than the other group members, a profit-maximizing player will try to maximize the chance of being elected in the voting stage. There are several voting equilibria, but all imply ex-ante equal chances to be elected as the delegate for one's group if all voters vote rationally. A corollary of this result is that there are no individual characteristics that play a role in the elections. All proofs can be found in Appendix A.

Hypothesis 1(c) for the election: All voting equilibria imply ex ante equal chances to be elected as the delegate in a group.

\subsection{Predictions based on other-regarding preferences}

In this section, we relax the self-interest assumption by considering a popular outcome-based otherregarding preference model: the inequity-aversion model by Fehr and Schmidt (1999). Fehr and Schmidt (1999) model fairness as a dislike of inequitable outcomes. Specifically, an inequity-averse player gains 
utility from her own payoff $\pi_{i}$, but suffers a utility loss if her own payoff differs from those of the other members in her reference group. The specific utility function is the following:

$$
U_{i}(\pi)=\pi_{i}-\alpha_{i} \frac{1}{n-1} \sum_{j \neq i} \max \left\{\pi_{j}-\pi_{i}, 0\right\}-\beta_{i} \frac{1}{n-1} \sum_{j \neq i} \max \left\{\pi_{i}-\pi_{j}, 0\right\},
$$

where the disadvantageous inequity-aversion parameter $\alpha_{i}$ and the advantageous inequity aversion parameter $\beta_{i}$ need to satisfy the following conditions: $\beta_{i} \leq \alpha_{i}$ and $0 \leq \beta_{i}<1$.

Table 1: Predictions for contributions in the stage game with inequity-averse preferences

\begin{tabular}{|c|c|c|}
\hline & Baseline & Delegation \\
\hline Part 3 & \multicolumn{2}{|c|}{$\begin{array}{l}{[\mathrm{A}] c_{i}=0, \text { if } \exists \beta_{i}<0.5, \text { or }} \\
{[\mathrm{B}] c_{i}=\mathrm{c} \in[0,20], \text { if } \forall \beta_{i} \geq 0.5}\end{array}$} \\
\hline $\begin{array}{l}\text { Part } 4 \\
\text { three-person reference group }\end{array}$ & $\begin{array}{l}{[\mathrm{A}] c_{i}=0, \text { if } \exists \beta_{i}<0.83, \text { or }} \\
{[\mathrm{B}] c_{i}=\mathrm{c} \in[0,20] \text { if } \forall \beta_{i} \geq 0.83}\end{array}$ & $\begin{array}{l}{[\mathrm{A}] c_{o}=20, \text { and } c_{D}=0 \text { if } \beta_{D}<0.33, \text { or }} \\
{[\mathrm{B}] c_{o}=c_{D}=0 \text { if } \beta_{D} \geq 0.33}\end{array}$ \\
\hline $\begin{array}{l}\text { Part } 4 \\
\text { nine-person reference group }\end{array}$ & $\begin{array}{l}{[\mathrm{A}] c_{i}=0, \text { if } \exists \beta_{i}<0.83, \text { or }} \\
\text { [B] } c_{i}=\mathrm{c} \in[0,20] \text { if } \forall \beta_{i} \geq 0.83\end{array}$ & $\begin{array}{l}{[\mathrm{A}] c_{o}=20, \text { and } c_{D}=0 \text { if } \exists \beta_{D}<0.83, \text { or }} \\
{[\mathrm{B}] c_{o}=c_{D}=20 \text { if } \forall \beta_{D} \geq 0.83}\end{array}$ \\
\hline
\end{tabular}

Notes: $i \ldots$ group member $i$, with three or nine members in the group, depending on the size of the reference group. $o \ldots$ ordinary group member (i.e. other group members); $D \ldots$ delegate.

Table 1 gives an overview of the parameter conditions required for the existence of cooperative equilibria using Fehr-Schmidt-preferences in the stage game of our experiment. The conditions assume common knowledge of the preferences, rationality and risk-neutrality. We discuss the intuition for the results only briefly and relegate a more detailed analysis including proofs to Appendix A. The analysis of Part 3 is straightforward. Inequity-aversion preferences can lead to equilibria in which all group members make the same positive contribution. These equilibria require that players' aversion against advantageous inequity is strong enough (i.e., $M P C R+\beta_{i} \geq 1$ ).

In Part 4, we derive predictions that distinguish between two different reference-group concepts: for a delegate or a group member the reference group can either be the own three-person group or the nineperson super-group. The distinction makes sense based on the well-established finding in the social identity literature that people differentiate between their in-group members and members of the out-group (see, e.g., Chen and Li, 2009). The three-person reference group implies that earnings of out-group members do not enter the utility function of delegates at all, while a nine-person reference group means that a delegate does not distinguish between in-group and out-group members. ${ }^{8}$ It turns out that how we define the size of the reference group does not affect equilibria in Baseline. This is an immediate consequence of the fact that the return of the public good is linear in proportions of contributions.

\footnotetext{
${ }^{8}$ Convex combinations of the two possibilities are not discussed in the following but are straightforward.
} 
Hypothesis 2(a) for Baseline: Part 3 predictions and Part 4 predictions for Baseline are identical. A cutoff-level of $\beta$ for all group members determines whether cooperative equilibria exist.

However, the size of the reference group affects the conditions that determine cooperative equilibria in Delegation. When the reference group is the three-person group, a delegate faces two sets of incentives. First, she has to trade-off her monetary earnings and income inequity within her group. Second, she has a monetary incentive to free ride on contributions of other groups, since income in other groups do not affect her utility. If the delegate is sufficiently selfish $\left(\beta_{D}<0.33\right)$, she will go for the selfish equilibrium $c_{D}=0 / c_{o}=20$. Interestingly, sufficient disutility from inequity by the delegate $\left(\beta_{D} \geq 0.33\right.$ ) leads to the non-cooperative equilibrium $c_{D}=c_{o}=0$. The inability to reach the cooperative equilibrium (or other equilibria with equal non-full contributions) is a consequence of the rather strong assumption that out-group members are not in the delegate's reference group. This means that out-group members' higher levels of utility from contributions simply do not matter.

When the reference group becomes the nine-person super-group, the weight of each in-group member in the social utility part of the delegate's utility function decreases from $1 / 2$ to $1 / 8$, while the weight of each out-group member increases from 0 to 1/8. Intuitively, free-riding on in-group members becomes comparatively more attractive, while free-riding on out-group members becomes less so, since the disutility from contributing less than them becomes larger. When all delegates are sufficiently averse to advantageous inequity $\left(\beta_{D} \geq 0.83\right)$, the full cooperative equilibrium is reached $\left(\mathrm{c}_{\mathrm{D}}=\mathrm{c}_{\mathrm{o}}=20\right.$.) Else, we get $c_{D}=0 / c_{o}=20$ that always dominates $c_{D}=c_{o}=0$ now. ${ }^{9}$

Hypothesis 2(b) for Delegation: Only three potential equilibria are sustainable: $\mathrm{c}_{\mathrm{D}}=\mathrm{c}_{\mathrm{o}}=20$, $\mathrm{c}_{\mathrm{D}}=\mathrm{c}_{\mathrm{o}}=0$, and $\mathrm{c}_{\mathrm{D}}=0 / \mathrm{c}_{\mathrm{o}}=20$. Which of them applies, depends on the specific assumptions regarding the size of the reference group and $\beta$-parameters of either the single delegate or all delegates in the super-group.

\footnotetext{
${ }^{9}$ The above analysis holds for the stage game. It is noteworthy that in the repeated game, there are many more equilibria, and they only require lower levels of $\beta$ because of the incentive to build a reputation as a cooperative delegate (e.g., Oechssler, 2013). Our delegation mechanism, however, implies a complication for the reputation-building process because of the election and of the chance that a delegate is suspended from her "job".
} 
We now turn to the election stage of our game. Again, we have to distinguish between the two reference-group concepts. Assume that the distribution of inequity-averse preferences is common knowledge to everyone. If the reference group is the three-person group, and every member is not sufficiently inequity-averse (i.e., $\beta<0.33$ ), subjects will vote for themselves and in equilibrium, everyone is equally likely to be elected. A candidate is strictly preferred only when she is sufficiently inequityaverse (i.e., $\beta>0.33$ ). If the reference group is the nine-person group sufficiently inequity-averse group members $(\beta \geq 0.83)$ are also preferred to become delegates. The reason is that, although self-interested voters assign the most favorable rank to themselves, they will strictly prefer a delegate who equalizes contributions in the entire group to one who free rides on them. However, as long as there is one group in which nobody is sufficiently inequity-averse, the equilibrium in which everyone votes for herself prevails. The reason is that it only takes one selfish delegate to destroy full cooperation equilibria. If one of the three delegates fully exploits her group members, her payoff will be much higher than the other two delegates, causing disadvantageous disutility to them. The effect of the disutility is strong enough to induce them to exploit their own group members as well.

Hypothesis 2(c): In Delegation, depending on the size of the reference groups and on the other delegates' inequity-aversion parameters, players with sufficient advantageous inequity aversion will be elected as delegates. However, players will vote for themselves and everybody is equally likely to become the delegate within her group if none of the candidates is sufficiently inequity-averse.

\section{Experimental results}

We organize the presentation of our results as follows. Section 4.1 compares average contributions and earnings across the two treatments. Section 4.2 studies contribution and allocation choices of the delegates. Section 4.3 analyzes how delegates are elected and what determines the rankings of the voters. Section 4.4 explains heterogeneous contribution dynamics across societies. Unless specified differently, the non-parametric tests in this section are two-sided Mann-Whitney rank sum tests, with each supergroup as a statistically strictly independent observation.

\subsection{Treatment differences}

Figure 1 presents the average group contributions to the public good by treatment. Before the treatment manipulation, the dynamics of contributions in both treatments are highly consistent with the previous literature: The average contributions amount to about $45 \%$ of the endowment in the first period of the 
public goods game, and then they decline steadily to about $15 \%$ by the eighth period (at the end of Part 3). The two treatments do not exhibit significant differences in contribution levels $(p>0.4)$, making sure that the initial experience is on average the same before the start of Part 4 in the two treatments.

After the introduction of the treatment variation, however, the two treatments exhibit stark differences. In Baseline, we observe the typical "restart" effect in the voluntary contribution mechanism, with an average contribution level of about $30 \%$, but contributions decay to less than $10 \%$ after a couple of periods. This pattern suggests that, without any institution, the free-riding incentive is dominant even in the repeated interaction, and social preferences are not strong enough to sustain high levels of cooperation.

In Delegation, average contributions start out at about $60 \%$ of the total endowment in period 1, but gradually decline to around $35 \%$ in the ultimate period of Part 4 . The treatment difference is obviously highly significant (averages for Part 4 are $9.6 \%$ versus $48.3 \% ; p<0.01$ ). Due to the linear nature of the public goods game, the significant differences in contributions directly translate into differences in earnings (see Figure B1 in Appendix B). Controlling for the decay and for the general level of cooperativeness on the group level measured in Part 3, the results of a random-effect regression analysis unambiguously confirm the findings from non-parametric tests (see Table B1 in Appendix B).

Figure 1. Average super-group contribution levels as a percentage of endowment in Part 3 and 4

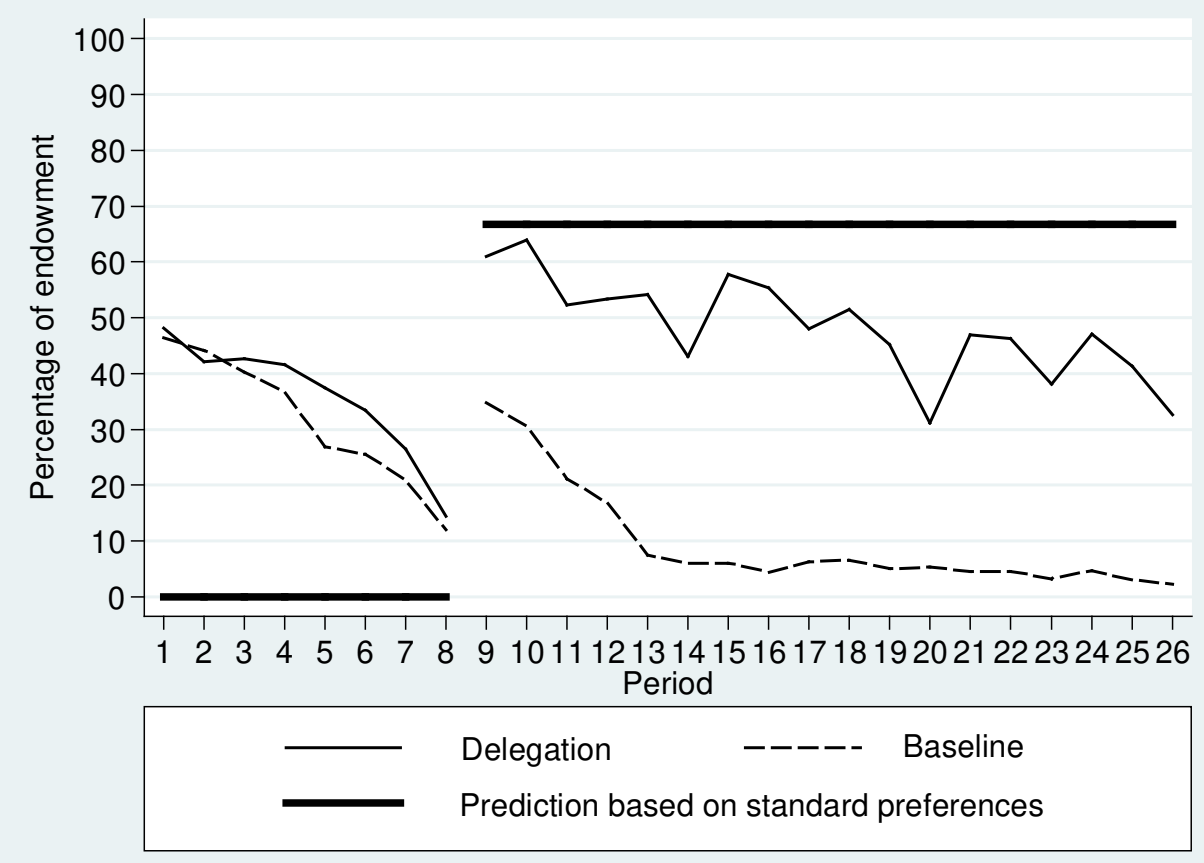


Predictions based on standard preferences indicate that if the delegates play the stage-game outcome by fully exploiting the other two group members, the average contributions at the society level should stay constant at $66.7 \%$ of the total endowment throughout the 18 periods of play in Delegation. This is clearly not the case. Contributions in Delegation are on average significantly below the benchmark $(p<$ 0.01). Result 1 summarizes the findings.

Result 1: Neither hypothesis 1(a) nor hypothesis 2(a) is fully supported. In Baseline, average contributions are significantly larger than zero, although they quickly decline to zero over time. Average contributions in Delegation are significantly higher than in Baseline; however, on average, they fall significantly below the theoretical prediction of $66.67 \%$. Delegation is significantly less efficient than standard theory predicts (the "P-inefficiency).

\subsection{Delegates' contribution and distribution choices}

To find out why the delegation mechanism deviates from the theoretical benchmarks and to what extent it might still be consistent with them, we first have a closer look at the choices of the delegates. We start by studying adjustments of their contributions across periods, using random-effect panel regressions. The dependent variable in Table 2 is the differences in contributions of the delegate's own group across two periods, either for the delegate herself, for the average of the other two members, or for both.

The significant coefficients $\beta_{2}$ and $\beta_{3}$, when pooling all data together, suggest that the delegates attempt to coordinate the contributions of their own groups with the average of the entire super-group. Specifically, if they realize that their own group over-contributed in the last period, they lower their contributions in the subsequent period $\left(\beta_{2}\right)$. Similarly, in case of under-contribution, the delegates adjust their own contributions upwards $\left(\beta_{3}\right)$. The insignificant coefficients $\beta_{4}$ and $\beta_{5}$ indicate that the contribution changes applied to the other two group members do not significantly differ from the changes applied to oneself as delegate. In other words, the delegates adjust contribution behavior similarly for the other group members as for themselves.

Not only that theory fails to predict the overall level of contributions, it also has problems to capture delegates' allocation decisions on the individual level. Only in $4.17 \%$ of all cases (18 out of 432) does a delegate behave exactly according to standard theory in the stage game by fully exploiting the other two members of her group, $13.66 \%$ of the time (59 out of 432) the delegate assigns zero contributions to everyone and $7.41 \%$ of the time (32 out of 432) she assigns full contributions to everyone.

Table 3 further analyzes the allocation decisions of the delegates. We first classify the elected delegates into three types based on their average contributions in Part 3, relative to the two other group 
members, and call them High, Middle, and Low delegates. Our first result indicates that there is a strong correlation between a delegate's own contribution in Part 3 and their allocation to the public goods in Part 4. High contributing delegates assign on average $55.4 \%$ of the total endowment to the public account, which is significantly higher than the assignment levels by middle or low contributors. ${ }^{10}$ The lower part of Table 3 reports contribution assignment frequencies, treating each allocation decision as an independent count. These figures indicate that, $85.4 \%$ of the time, the elected delegates choose equal contributions for all group members. This is particularly true if the delegate has been the high contributor in her group: Roughly $90 \%$ of the time she will implement an equal contribution vector, among which $13 \%$ of the time she requires all group members to contribute fully. Interestingly, middle and low contribution delegates also assign equal contribution levels with very high frequencies ( $80 \%$ and $81.9 \%$, respectively). Overall, only about $10-15 \%$ of the time do they attempt to exploit other group members.

Table 2. Random-effect regressions on contribution dynamics

\begin{tabular}{|c|c|c|c|}
\hline Changes of contributions across periods & All & Delegates & Average of others \\
\hline$\beta_{1}$ : Changes apply to the other two members (=1 if yes) & $\begin{array}{l}-0.442 \\
(0.305)\end{array}$ & - & - \\
\hline$\beta_{2}$ : Positive deviation from the super-group average (t-1) & $\begin{array}{l}-0.855^{* * *} \\
(0.148)\end{array}$ & $\begin{array}{l}-0.829^{* * *} \\
(0.164)\end{array}$ & $\begin{array}{l}-0.536^{* *} \\
(0.228)\end{array}$ \\
\hline$\beta_{3}$ : Negative deviation from the super-group average (t-1) & $\begin{array}{l}0.557^{* * *} \\
(0.139)\end{array}$ & $\begin{array}{l}0.519^{* * *} \\
(0.117)\end{array}$ & $\begin{array}{l}0.532^{* * *} \\
(0.128)\end{array}$ \\
\hline $\begin{array}{l}\beta_{4} \text { : Changes apply to the other two members } \times \text { Positive } \\
\text { deviation from super-group average }(\mathrm{t}-1)\end{array}$ & $\begin{array}{c}0.304 \\
(0.214)\end{array}$ & - & - \\
\hline $\begin{array}{l}\beta_{5}: \text { Changes apply to the other two members } \times \text { Negative } \\
\text { deviation from super-group average }(\mathrm{t}-1)\end{array}$ & $\begin{array}{c}0.017 \\
(0.075)\end{array}$ & - & - \\
\hline$\beta_{6}:$ Period & $\begin{array}{l}-0.098 \\
(0.067)\end{array}$ & $\begin{array}{l}-0.109^{*} \\
(0.060)\end{array}$ & $\begin{array}{l}-0.051 \\
(0.083)\end{array}$ \\
\hline Constant & $\begin{array}{l}-0.186 \\
(0.632)\end{array}$ & $\begin{array}{c}0.128 \\
(0.578)\end{array}$ & $\begin{array}{l}-0.907 \\
(0.712)\end{array}$ \\
\hline $\begin{array}{l}\mathrm{R}^{2} \text { overall } \\
\text { No. of observations }\end{array}$ & $\begin{array}{c}0.141 \\
576\end{array}$ & $\begin{array}{c}0.167 \\
288 \\
\end{array}$ & $\begin{array}{c}0.113 \\
288 \\
\end{array}$ \\
\hline
\end{tabular}

Notes: ${ }^{*} p<.1,{ }^{k * *} p<.05,{ }^{*, *} p<.01$. Robust standard errors (clustered at the group level) are reported in parentheses. In particular, the variable "Changes apply to the other two members" is a dummy variable equal to 1 if the dependent variable is the average change of contributions for the other two members across periods of each period. "Positive (Negative) deviation from the super-group average" measures the amount group average contributions exceeds (falls short of) that of the supergroup averages in the last period.

\footnotetext{
${ }^{10}$ The random-effect regression results in Table B2 of Appendix B support this claim.
} 
Such high proportions of equal contributions are consistent with the following explanations. First, subjects' behavior is better accounted for by some version of the other-regarding preference models or a certain form of conditional cooperation. Second, at least some delegates mimic the strategy of the otherregarding type to increase their chances to be re-elected. ${ }^{11}$ To tear apart the relative importance of preference and strategic concerns, we look into the correlation between the allocation decisions of delegates in Part 2 (the one-shot allocation game) and their decisions in Part 4. We exclude data in the last three periods of Part 4 for the moment, since delegates have no incentive anymore to build up reputation.

Table 3. Decisions of the elected delegates

\begin{tabular}{lcccc}
\hline & \multicolumn{5}{c}{ Contribution ranks of delegates in Part 4 } \\
\hline \multirow{2}{*}{ Contributions in \% (mean) } & High & Middle & Low & All \\
Contributions in \% (standard dev.) & 55.4 & 40.7 & 40 & 48.3 \\
& 26.3 & 25.2 & 25.3 & 26.8 \\
\hline \multicolumn{5}{c}{ Distribution of allocation decisions (in \%) } \\
\hline EQUAL & 89.8 & 80.0 & 81.9 & 85.4 \\
FULL & 12.9 & 2.2 & 0.0 & 7.4 \\
EXPLOIT ONE & 4.0 & 9.6 & 1.4 & 5.3 \\
OTHER (ALTRUISTIC) & 6.2 & 7.4 & 11.1 & 7.4 \\
\hline No. of observations & 0.0 & 3.0 & 5.6 & 1.9 \\
\hline \hline
\end{tabular}

Notes: FULL means that the delegate contributes the entire endowments of all three group members to the global public good. EQUAL means that the delegate lets every member contribute the same to the global public goods (including full contributions). EXPLOIT ONE means that the delegate contributes the same as or more than one group member and forces the other member to contribute the most (uniquely) of the three. EXPLOIT BOTH means that the delegate contributes the least (uniquely) among the three. OTHER includes all contribution vectors of altruistic types (delegate contributes the most (uniquely or together with one other group member)).

Table 4. Correlation between delegates' distribution preferences in Part 2 and decisions in Part 4 (except for the last three periods)

\begin{tabular}{cc|ccccc}
\hline \hline Part 2 & Part 4 & Equal & $\begin{array}{c}\text { Exploit } \\
\text { one member }\end{array}$ & $\begin{array}{c}\text { Exploit } \\
\text { both members }\end{array}$ & Others & Total \\
\hline Equal & 157 & 10 & 0 & 1 & 168 \\
Exploit one member & 3 & 0 & 0 & 0 & 3 \\
Exploit both members & 164 & 9 & 10 & 6 & 189 \\
\hline
\end{tabular}

\footnotetext{
${ }^{11}$ A feeling of responsibility on the side of the delegates could be another reason that leads to equal contributions. However, we cannot directly assess its influence and disentangle it from other-regarding preferences in our setup.
} 


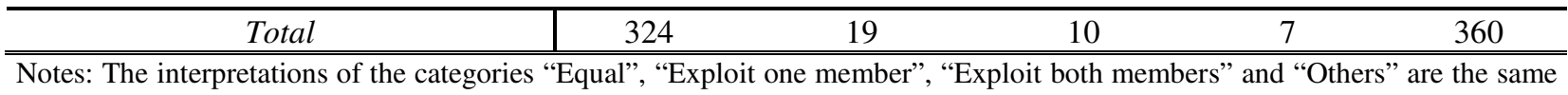
as in Table 3.

The main observation from Table 4 is that both preferences and strategic concerns explain the behavioral pattern of delegates. The allocators that shared equally in Part 2, if elected as a delegate in Part 4 , continue assigning equal contributions for all group members in more than $90 \%$ of cases (157/168). The exploiting types based on the behavior in Part 2, on the other hand, also equalize contributions in about $85 \%$ of the time (164 out of 189). Result 2 summarizes the above findings.

Result 2: Neither Hypothesis 1(b) or Hypothesis 2(b) is fully supported when looking at the contribution assignment decisions of the delegates: Instead of completely free-riding on the contributions of the other two group members, they most frequently assign equal non-zero, medium levels of contributions for everyone. Moreover, contributions decline over time in both treatments.

\subsection{Elections and rankings of delegates}

\subsubsection{Election of delegates}

From the previous sections, two main patterns in contradiction with standard theoretical predictions arise. First, contributions fall below the efficiency benchmark, and exhibit a declining trend even in Delegation. Second, the elected delegates mostly assign equal contributions within their groups. This section offers a set of empirical analyses from the elections and from ranking data that allow for a better understanding of our main findings so far.

Table 5. Summary statistics on the first election

\begin{tabular}{lccc}
\hline & Percentage of rank 1 & Average rank assigned & Number elected \\
\hline Self & 63.9 & & \\
High contributor & 55.6 & 1.6 & 19 \\
Middle contributor & 26.4 & 2 & 3 \\
Low contributor & 18.1 & 2.4 & 2 \\
\hline No. of observations & 72 & 72 & 24 \\
\hline \hline
\end{tabular}

We start by presenting simple summary statistics from the very first election in Table 5. Despite the obvious fact that a lot of subjects assign the most favorable rank to themselves, the majority of groups still favor high contributors as their delegates. In particular, 55.6\% of the most preferred ranks go to the high contributor in the group, whereas only $18.1 \%$ go to the low contributor. As a result, high contributors receive the most favorable ranks (the lowest average), and are elected most frequently (in 19 out of 24 
groups). The regression analysis in Table B3 in Appendix B further supports this result. In this regression, the outcome of the first election depends on choices of a subject in (each of) the three previous parts. In all the specifications, the high contributor is more likely to be elected, regardless of whether we control for cooperative or distributive preferences (based on behavior in Parts 1 and 2) or not.

Table 6. Election analysis in later periods (Probit model)

\begin{tabular}{|c|c|c|c|c|}
\hline $\begin{array}{l}\text { Dependent variable: } \text { whether a subject is } \\
\text { elected }(1=y e s)\end{array}$ & Model 1 & Model 2 & Model 3 & Model 4 \\
\hline$\beta_{1}$ : Incumbent delegate (=1 if yes) & $\begin{array}{l}2.345^{* * *} \\
(0.575)\end{array}$ & $\begin{array}{l}2.345^{* * *} \\
(0.574)\end{array}$ & $\begin{array}{l}2.335^{* * *} \\
(0.580)\end{array}$ & $\begin{array}{l}2.401 * * * \\
(0.591)\end{array}$ \\
\hline$\beta_{2}:$ Part 3 rank within group & $\begin{array}{l}-0.086 \\
(0.149)\end{array}$ & $\begin{array}{l}-0.085 \\
(0.144)\end{array}$ & $\begin{array}{l}-0.077 \\
(0.152)\end{array}$ & $\begin{array}{l}-0.049 \\
(0.151)\end{array}$ \\
\hline $\begin{array}{l}\beta_{3} \text { : Incumbent delegate } \times \text { Part } 3 \text { rank } \\
\text { within group }\end{array}$ & $\begin{array}{c}-0.277^{* *} \\
(0.196)\end{array}$ & $\begin{array}{l}-0.277 \\
(0.197)\end{array}$ & $\begin{array}{l}-0.275 \\
(0.195)\end{array}$ & $\begin{array}{l}-0.317^{*} \\
(0.192)\end{array}$ \\
\hline $\begin{array}{l}\beta_{4}: \text { Positive deviation from super-group } \\
\text { average }\end{array}$ & $\begin{array}{c}0.123 \\
(0.082)\end{array}$ & $\begin{array}{l}0.123 \\
(0.84)\end{array}$ & $\begin{array}{c}0.106 \\
(0.077)\end{array}$ & $\begin{array}{c}0.116 \\
(0.082)\end{array}$ \\
\hline $\begin{array}{l}\beta_{5}: \text { Incumbent delegate } \times \text { Positive } \\
\text { deviation from the super-group average }\end{array}$ & $\begin{array}{l}-0.372^{* *} \\
(0.194)\end{array}$ & $\begin{array}{l}-0.373^{*} \\
(0.200)\end{array}$ & $\begin{array}{l}-0.349^{* * *} \\
(0.194)\end{array}$ & $\begin{array}{c}-0.370^{* * *} \\
(0.192)\end{array}$ \\
\hline $\begin{array}{l}\beta_{6}: \text { Negative deviation from the super- } \\
\text { group average }\end{array}$ & $\begin{array}{c}0.076 \\
(0.082)\end{array}$ & $\begin{array}{c}0.076 \\
(0.082)\end{array}$ & $\begin{array}{c}0.081 \\
(0.085)\end{array}$ & $\begin{array}{c}0.073 \\
(0.018)\end{array}$ \\
\hline $\begin{array}{l}\beta_{7:} \text { Incumbent delegate } \times \text { Negative } \\
\text { deviation from the super-group average }\end{array}$ & $\begin{array}{l}-0.160 \\
(0.185)\end{array}$ & $\begin{array}{l}-0.160 \\
(0.185)\end{array}$ & $\begin{array}{l}-0.159 \\
(0.184)\end{array}$ & $\begin{array}{l}-0.155 \\
(0.187)\end{array}$ \\
\hline$\beta_{8:}$ Average extent of exploiting both & $\begin{array}{c}0.051^{* * *} \\
(0.017)\end{array}$ & $\begin{array}{l}0.051^{* * * *} \\
(0.017)\end{array}$ & $\begin{array}{c}0.055^{* * *} \\
(0.017)\end{array}$ & $\begin{array}{c}0.065^{* * *} \\
(0.019)\end{array}$ \\
\hline $\begin{array}{l}\beta_{9:} \text { Incumbent delegate } \times \text { Average extent } \\
\text { of exploiting both }\end{array}$ & $\begin{array}{c}-0.754^{* * *} \\
(0.133)\end{array}$ & $\begin{array}{c}-0.754^{* * * *} \\
(0.131)\end{array}$ & $\begin{array}{c}-0.783^{* * *} \\
(0.141)\end{array}$ & $\begin{array}{c}-0.802^{* * *} \\
(0.160)\end{array}$ \\
\hline$\beta_{10:}$ Election period (1-5) & $\begin{array}{c}0.016 \\
(0.014)\end{array}$ & $\begin{array}{c}0.015 \\
(0.013)\end{array}$ & $\begin{array}{c}0.012 \\
(0.014)\end{array}$ & $\begin{array}{c}0.014 \\
(0.014)\end{array}$ \\
\hline$\beta_{11}$ : Constant & $\begin{array}{c}0.010 \\
(0.011)\end{array}$ & $\begin{array}{c}0.010 \\
(0.011)\end{array}$ & $\begin{array}{c}0.006 \\
(0.012)\end{array}$ & $\begin{array}{c}0.008 \\
(0.012)\end{array}$ \\
\hline Additional controls & None & $\begin{array}{c}\text { Part } 1 \\
\text { unconditional } \\
\text { contribution }\end{array}$ & $\begin{array}{c}\text { Part } 1 \\
\text { cooperative } \\
\text { preferences }\end{array}$ & $\begin{array}{c}\text { Part } 2 \\
\text { distributive } \\
\text { preferences }\end{array}$ \\
\hline Log-likelihood & -173.87 & -173.87 & -172.57 & -171.88 \\
\hline No. of observations & 360 & 360 & 360 & 350 \\
\hline \multicolumn{5}{|c|}{$\begin{array}{l}\text { Notes: }{ }^{*} p<.1,{ }^{* *} p<.05,{ }^{* * *} p<.01 \text {. Robust standard errors (clustered at the group level) are reported in parentheses. In } \\
\text { particular, the variable "Incumbent delegate" is a dummy variable equal to } 1 \text { if this candidate was the previous delegate in the last } \\
\text { three periods. "Positive (Negative) deviation from the super-group average" measures the amount the group average } \\
\text { contributions exceed (fall short of) that of the super-group average in the past three periods. The variable "Incumbent delegatex } \\
\text { Positive (Negative) deviation from the super-group average" captures the interaction term between these two variables. The } \\
\text { variable "Average extent of exploiting both" measures the contribution difference between the delegate and the average of the } \\
\text { other two members in the past three periods (only if the delegate exploited the other two members). "Election period" takes the }\end{array}$} \\
\hline
\end{tabular}


value 1 to 5 as there are six elections altogether in Part 4 (and election 1 is omitted). In different specifications, we add the choices of a subject in previous parts of the experiment as additional controls.

Table 6 reports the regression analysis for later elections, i.e. the five elections in Part 4 of the experiment excluding the very first. In the first election, the only information voters could condition their ranking on is the average contributions of all players in Part 3. In later elections, however, the voters have extra information on the performance of the incumbent delegate and the previous group-level contributions of the other two groups.

The results from Table 6 indicate that there is significant path dependency to elect the incumbent delegate $\left(\beta_{1}\right)$. The coefficient $\beta_{5}$ is significantly negative, which means that the incumbent delegate is less likely to be re-elected, the more the group she represented was exploited by the other groups in the society during her tenure. Moreover, the more delegates exploit both of their own group members during their tenure, the less likely they will be re-elected $\left(\beta_{9}\right) .{ }^{12}$ Result 3 summarizes the main findings.

Result 3: Hypothesis 1(c) is rejected while Hypothesis 2(c) is partly supported: Voters prefer pro-social delegates (high contributors in Part 3), but the effect is only marginally significant in the regressions. In later elections, incumbent delegates have a much higher chance to be re-elected. However, their chances decrease, (i) the more the average contributions of their groups exceed that of the society's average, and (ii) the higher contribution levels they choose for the other two group members compared to their own contributions.

The above findings are very much consistent with what we observe as the stylized behavior of the elected delegates. In particular, group members use elections as a device to topple unsuccessful delegates, i.e. if the delegate was exploited by other groups. They also refrain to re-elect delegates that act selfishly. In response, the elected delegates assign equal contributions for all members within their groups. Moreover, they try not to over-contribute compared to the two other groups within the society. The latter motive leads to the decaying trend in contributions that was surprising at first sight because it is at odds with most theoretical predictions.

\subsubsection{Ranking of delegates}

Individual ranking behavior in the course of the election provides a more detailed picture of the election. We employ ordered logit regressions to study the determinants of the ranks that voters assign to different candidates. Similarly to the previous sub-section, we run regressions separately for the first election and

\footnotetext{
${ }^{12}$ All results remain robust if we only consider the final election period (see Table B4 in Appendix B).
} 
the later ones, since ranking behavior might be different if the interaction has a history, which is true from the second election onwards. Not surprisingly, the ranking pattern is highly consistent with the voting outcome: Voters have a strong preference to vote for themselves. However, after controlling for that, high contributors are the most preferred candidates. Table B5 in the Appendix provides the regression results.

The aggregated ranking behavior in later periods is more easily described when we distinguish again between high, middle and low contributors, based on the behavior of group members in Part 3 of the experiment. Table 7 provides the results of regressions, with voter $i$ 's rank assigned to candidate $j$ (excluding $i$, i.e. herself).

Table 7. Ranking analysis in later elections (ordered logit model)

\begin{tabular}{|c|c|c|c|c|}
\hline $\begin{array}{l}\text { Dependent variable: voter i's rank to candidate } \\
\mathrm{j} \text { (excluding i, i.e. herself) }\end{array}$ & $\begin{array}{c}\text { High } \\
\text { contributor }\end{array}$ & $\begin{array}{c}\text { Middle } \\
\text { contributor }\end{array}$ & $\begin{array}{c}\text { Low } \\
\text { contributor }\end{array}$ & $\begin{array}{l}\text { Aggregate } \\
\text { data }\end{array}$ \\
\hline$\beta_{1}$ : Incumbent delegate (= 1 if yes) & $\begin{array}{l}-5.697^{* * * *} \\
(2.073)\end{array}$ & $\begin{array}{c}0.309 \\
(0.697)\end{array}$ & $\begin{array}{l}-2.005^{*} \\
(1.150)\end{array}$ & $\begin{array}{l}-0.817 \\
(0.627)\end{array}$ \\
\hline$\beta_{2}$ : Rank part 3 in group & $\begin{array}{c}0.893 \\
(0.581)\end{array}$ & $\begin{array}{l}0.536^{* *} \\
(0.269)\end{array}$ & $\begin{array}{l}-0.725 \\
(0.566)\end{array}$ & $\begin{array}{l}0.311^{*} \\
(0.184)\end{array}$ \\
\hline$\beta_{3}:$ Incumbent delegate $\times$ Rank part 3 in group & $\begin{array}{l}1.803^{* *} \\
(0.769)\end{array}$ & $\begin{array}{l}-0.632^{*} \\
(0.370)\end{array}$ & $\begin{array}{c}0.763 \\
(0.555)\end{array}$ & $\begin{array}{c}0.013 \\
(0.275)\end{array}$ \\
\hline $\begin{array}{l}\beta_{4} \text { : Incumbent delegate } \times \text { Positive deviation } \\
\text { from super-group average }\end{array}$ & $\begin{array}{l}0.928^{* * *} \\
(0.316)\end{array}$ & $\begin{array}{l}-0.078 \\
(0.362)\end{array}$ & $\begin{array}{l}-0.271 \\
(0.315)\end{array}$ & $\begin{array}{l}-0.027 \\
(0.201)\end{array}$ \\
\hline $\begin{array}{l}\beta_{5}: \text { Incumbent delegate } \times \text { Negative deviation } \\
\text { from super-group average }\end{array}$ & $\begin{array}{c}0.063 \\
(0.139)\end{array}$ & $\begin{array}{c}0.034 \\
(0.184)\end{array}$ & $\begin{array}{l}-0.209 \\
(0.206)\end{array}$ & $\begin{array}{l}-0.106 \\
(0.124)\end{array}$ \\
\hline $\begin{array}{l}\beta_{6}: \text { Incumbent delegate } \times \text { Average amount of } \\
\text { exploiting both group members }\end{array}$ & $\begin{array}{c}4.159^{* * *} \\
(0.825)\end{array}$ & $\begin{array}{l}0.209^{* *} \\
(0.082)\end{array}$ & $\begin{array}{l}0.770^{* *} \\
(0.311)\end{array}$ & $\begin{array}{c}0.464 \\
(0.311)\end{array}$ \\
\hline$\beta_{7}$ : Re-election period & $\begin{array}{l}-0.005 \\
(0.063)\end{array}$ & $\begin{array}{c}0.058 \\
(0.048)\end{array}$ & $\begin{array}{l}-0.031 \\
(0.037)\end{array}$ & $\begin{array}{c}0.009 \\
(0.026)\end{array}$ \\
\hline Log-likelihood & -212.76 & -252.65 & -229.52 & -722.76 \\
\hline No. of observations & 240 & 240 & 240 & 720 \\
\hline
\end{tabular}

Notes: ${ }^{*} p<.1,{ }^{* *} p<.05,{ }^{* * *} p<.01$. Robust standard errors (clustered at each voter) are reported in parentheses. All variables here refer to candidates except for the control variable "Re-election period". "Rank part 3 in group" refers to the ranking within the subgroup of considered contributors in the first three columns.

The ranking patterns of the high contribution voters are highly consistent with the election outcomes. Namely, voters assign more favorable ranks to the incumbent delegate $\left(\beta_{1}\right)$, and less favorable ranks if the incumbent delegate is a low contributor in Part $3\left(\beta_{3}\right)$. Negative ranking consequences for the candidate are, furthermore, due to contributing more than the super-group average $\left(\beta_{4}\right)$ or by forcing the other two members to contribute more than oneself in the previous periods $\left(\beta_{6}\right)$. The ranking patterns for middle and low contribution candidates are less robust, but note that they are also less relevant, because it is the high 
contributors that become delegates most often. The only consistent negative effect on the ranking is exploitation of the two other group members by the delegate $\left(\beta_{6}\right)$. Result 4 summarizes the findings from our analysis.

Result 4: Voters unambiguously assign favorable ranks to high contributors in the first election. In later elections, the ranking pattern of the high contribution voters is in line with the aggregated election outcome described in Result 3. Delegates who exploit the two other group members are toppled consistently.

\subsection{Contribution dynamics and preference heterogeneity}

Figure 2 gives a descriptive overview of contributions over time by each of the three groups in a supergroup. The abbreviations on top of each panel $(\mathrm{Bx}, \mathrm{Dx})$ indicate the super-group numbers in our two treatments (B for Baseline and D for Delegation).

There are stark differences between the Baseline and the Delegation treatments in terms of the dynamics. In Baseline, most super-groups quickly converge to zero contributions after three to four periods of interaction. The dynamics in Delegation is much more heterogeneous. Figure 4 suggests that very few delegates initially start with full cooperation (two groups in D5 and one group in D7). Most of them contribute cautiously (i.e., about half of the group endowment) to gauge the inclination to cooperate by the other two delegates in the society. The delegates in some super-groups (such as D3, D7 and to a lesser extent D8) manage to coordinate and sustain a certain cooperation level throughout Part 4 (56\% for D3, 58\% for D7, and 54.4\% for D8). Some other super -groups (such as D1, D2 and D4) exhibit a lot of fluctuations and a lower overall cooperation level (36.0\% for D1, 31\% for D2, and 25\% for D4). Only one super-group consistently contribute more than the benchmark based on self-regarding preferences (76.5\% for D5). Results from a hierarchical cluster analysis confirm that the contribution dynamics of the eight super-groups can be divided into three categories: successful (D5), failed (D1, D2, D4) and mixed (D3, D6, D7, D8).

What causes electoral delegation to perform worse in some super-groups than in others? One common feature of the three failed super-groups is that contributions of some groups fall to a very low level (usually zero) in early periods. In the first three periods, the average contributions of the three failed super-groups are already significantly lower than those in other super-groups (8.75 versus $13.64, p<$ 0.05). Another feature is that failed super-groups exhibit a steady downward sloping trend in contributions, while the more successful super-groups are better at coordinating at a certain positive contribution level. Based on these features, we conjecture that some delegates in failed super-groups 
attempt to free ride on the other groups in the initial periods, triggering an immediate response to decrease contributions by other group delegates in subsequent periods, which is in contrast to standard theoretical predictions if it happens below the threshold of the $66.7 \%$ contribution level.

Figure 2. Contribution dynamics of each super-group in Part 3 and Part 4

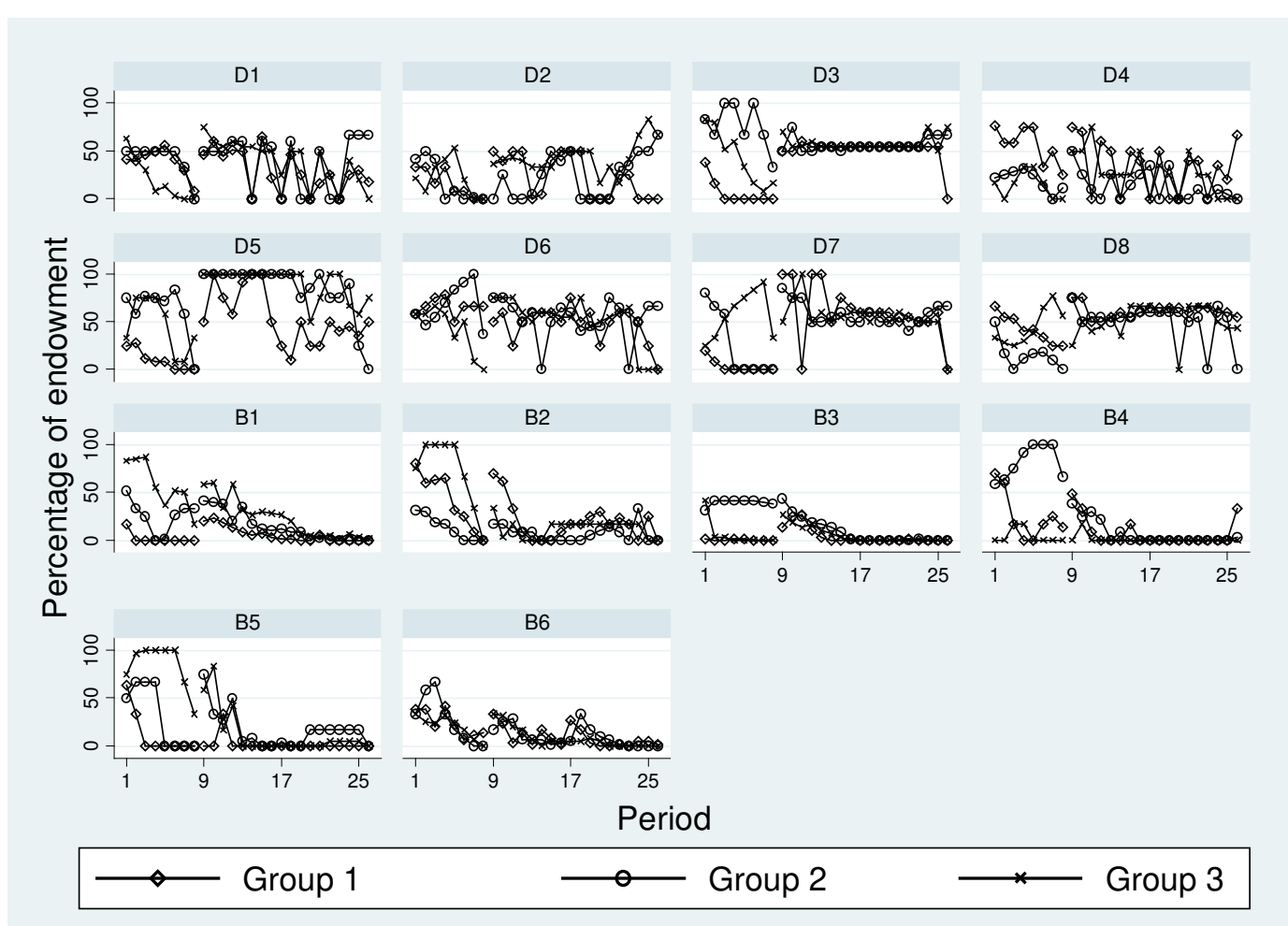

Notes: The letters combined with numbers in each panel represent treatment and super-group number (B stands for Baseline, and D stands for Delegation).

To provide more rigorous evidence, we analyze contribution dynamics separately for failed and other super-groups. Results of the regression models are reported in Table 8. The contribution dynamics in failed super-groups exhibit two distinctive features from those of other super-groups. Firstly, the significance of coefficient $\beta_{4}$ suggests that some delegates attempt to exploit their fellow group members. While the delegates lower contributions for everyone, the magnitude of the decrease is higher for herself than for the other two members within her group. Delegates in other super-groups, on the other hand, treat their fellow group members equally, since the corresponding coefficient is not significant in the regression that only contains successful and mixed super-groups (Chow-test, $p<0.05$ ). Last but not least, while delegates in other super-groups increase contributions significantly when they learn that they have under-contributed compared to the others $\left(\beta_{3}\right)$, delegates in failed super-groups are insensitive in this respect (Chow-test, $p<0.1)$. 
Table 8. Contribution dynamics conditional on the performance of the super-groups

\begin{tabular}{|c|c|c|c|}
\hline $\begin{array}{l}\text { Dependent variable: Changes of contributions } \\
\text { across periods }\end{array}$ & $\begin{array}{c}\text { Failed } \\
\text { super-groups } \\
(\text { No. } 1,2,4) \\
\end{array}$ & $\begin{array}{c}\text { Other } \\
\text { super-groups } \\
(\text { No. 3, 6,7,8) } \\
\end{array}$ & $\begin{array}{c}\text { Aggregate data } \\
\text { (All } \\
\text { super-groups) }\end{array}$ \\
\hline $\begin{array}{l}\beta_{1}: \text { Changes apply to the other two members } \\
(=1 \text { if yes })\end{array}$ & $\begin{array}{l}-0.581 \\
(0.450)\end{array}$ & $\begin{array}{l}-0.715 \\
(0.563)\end{array}$ & $\begin{array}{l}-0.442 \\
(0.305)\end{array}$ \\
\hline $\begin{array}{l}\beta_{2} \text { : Positive deviation from the super-group } \\
\text { average }\end{array}$ & $\begin{array}{l}-1.079^{* * *} \\
(0.269)\end{array}$ & $\begin{array}{l}-1.136^{* * *} \\
(0.179)\end{array}$ & $\begin{array}{l}-0.855^{* * *} \\
(0.148)\end{array}$ \\
\hline $\begin{array}{l}\beta_{3}: \text { Negative deviation from the super-group } \\
\text { average }\end{array}$ & $\begin{array}{c}0.448 \\
(0.310)\end{array}$ & $\begin{array}{l}0.332^{* * *} \\
(0.115)\end{array}$ & $\begin{array}{l}0.557^{* * *} \\
(0.139)\end{array}$ \\
\hline $\begin{array}{l}\beta_{4}: \text { Changes apply to the other two members } \times \\
\text { Positive deviation from super-group average }\end{array}$ & $\begin{array}{l}0.261^{* * *} \\
(0.093)\end{array}$ & $\begin{array}{c}0.641 \\
(0.697)\end{array}$ & $\begin{array}{c}0.304 \\
(0.214)\end{array}$ \\
\hline $\begin{array}{l}\beta_{5}: \text { Changes apply to the other two members } \times \\
\text { Negative deviation from super-group average }\end{array}$ & $\begin{array}{l}-0.030 \\
(0.102)\end{array}$ & $\begin{array}{c}0.288 \\
(0.200)\end{array}$ & $\begin{array}{c}0.017 \\
(0.075)\end{array}$ \\
\hline$\beta_{6}:$ Period & $\begin{array}{c}0.077 \\
(0.112)\end{array}$ & $\begin{array}{c}-0.170^{* *} \\
(0.081)\end{array}$ & $\begin{array}{c}-0.098 \\
(0.067)\end{array}$ \\
\hline Constant & $\begin{array}{c}-1.208 \\
(1.384)\end{array}$ & $\begin{array}{c}0.759 \\
(0.617)\end{array}$ & $\begin{array}{l}-0.186 \\
(0.632)\end{array}$ \\
\hline $\begin{array}{l}\mathrm{R}^{2} \text { overall } \\
\text { No. of observations }\end{array}$ & $\begin{array}{c}0.177 \\
216\end{array}$ & $\begin{array}{c}0.116 \\
288\end{array}$ & $\begin{array}{c}0.141 \\
576\end{array}$ \\
\hline
\end{tabular}

Despite the fact that contribution dynamics differ between successful and the failed super-groups, there are no systematically different patterns in terms of elections. Table 9 reports random-effect Probit models that assess this issue. They indicate that there is path dependency for both successful and failed groups in that the previous delegate is more likely to be elected $\left(\beta_{1}\right)$. When the previous delegates have over-contributed compared to the other groups, they are less likely to be re-elected $\left(\beta_{4}\right)$, although not significantly so, perhaps due to the lack of statistical power, given the relatively small number of observation per model. Moreover, appropriative delegates who assign lower contributions for themselves than for the two other group members are usually replaced even in failed super-groups $\left(\beta_{6}\right)$. Result 5 summarizes our main findings.

Result 5. Heterogeneity between super-groups in terms of success lies in contribution dynamics combined with the equal contribution norm rather than the way delegates are elected. 
Table 9. Election analysis in later periods for failed and successful super-groups (Probit model)

\begin{tabular}{|c|c|c|c|}
\hline $\begin{array}{l}\text { Dependent variable: whether a subject } \\
\text { is elected }\end{array}$ & $\begin{array}{c}\text { Failed } \\
\text { super-groups } \\
(\text { No. } 1,2,4)\end{array}$ & $\begin{array}{c}\text { Other } \\
\text { super-groups } \\
\text { (No. } 3,6,7,8)\end{array}$ & $\begin{array}{c}\text { Aggregate data } \\
\text { (All } \\
\text { super-groups) }\end{array}$ \\
\hline$\beta_{1}$ : Incumbent delegate (= 1 if yes) & $\begin{array}{l}2.302^{* *} \\
(1.002)\end{array}$ & $\begin{array}{l}2.197^{* * *} \\
(0.670)\end{array}$ & $\begin{array}{l}2.156^{* * * * *} \\
(0.511)\end{array}$ \\
\hline$\beta_{2}$ : Part 3 rank within group & $\begin{array}{l}-0.067 \\
(0.247)\end{array}$ & $\begin{array}{c}0.008 \\
(0.159)\end{array}$ & $\begin{array}{l}-0.093 \\
(0.135)\end{array}$ \\
\hline $\begin{array}{l}\beta_{3} \text { : Incumbent delegate } \times \text { Part } 3 \text { rank } \\
\text { within group }\end{array}$ & $\begin{array}{l}-0.342 \\
(0.305)\end{array}$ & $\begin{array}{l}-0.253 \\
(0.248)\end{array}$ & $\begin{array}{l}-0.271 \\
(0.185)\end{array}$ \\
\hline $\begin{array}{l}\beta_{4} \text { : Incumbent delegate } \times \text { Positive } \\
\text { deviation from the super-group average }\end{array}$ & $\begin{array}{l}-0.320 \\
(0.238)\end{array}$ & $\begin{array}{l}-0.168 \\
(0.219)\end{array}$ & $\begin{array}{l}-0.250^{* *} \\
(0.115)\end{array}$ \\
\hline $\begin{array}{l}\beta_{5}: \text { Incumbent delegate } \times \text { Negative } \\
\text { deviation from the super-group average }\end{array}$ & $\begin{array}{l}-0.223 \\
(0.264)\end{array}$ & $\begin{array}{l}-0.210 \\
(0.159)\end{array}$ & $\begin{array}{l}-0.083 \\
(0.105)\end{array}$ \\
\hline $\begin{array}{l}\beta_{6}: \text { Incumbent delegate } \times \text { Average extent } \\
\text { of exploiting both }\end{array}$ & $\begin{array}{l}-0.559^{*} \\
(0.335)\end{array}$ & - & $\begin{array}{c}-0.703^{* * *} \\
(0.125)\end{array}$ \\
\hline$\beta_{7}$ : Re-election period & $\begin{array}{c}0.000 \\
(0.022)\end{array}$ & $\begin{array}{l}-0.004 \\
(0.025)\end{array}$ & $\begin{array}{c}0.012 \\
(0.013)\end{array}$ \\
\hline$\beta_{8}:$ Constant & $\begin{array}{l}-0.784 \\
(0.523) \\
\end{array}$ & $\begin{array}{c}-1.007 * * * \\
(0.317) \\
\end{array}$ & $\begin{array}{c}-0.823^{* * *} \\
(0.290) \\
\end{array}$ \\
\hline $\begin{array}{l}\text { log-likelihood } \\
\text { No. of observations }\end{array}$ & $\begin{array}{r}-68.46 \\
135\end{array}$ & $\begin{array}{c}-86.12 \\
178\end{array}$ & $\begin{array}{c}-175.73 \\
360\end{array}$ \\
\hline
\end{tabular}

One possible explanation could be that, as long as a previous delegate from a failed super-group protects her group members from being exploited by other groups and does not exploit fellow group members, her performance is viewed as satisfactory, and hence she is re-elected. If this is true, the failed super-groups might elect relatively more defensive and conservative delegates compared to their successful counterparts. According to Fischbacher and Gächter (2010), the observed dynamics of contributions in a public goods game could be influenced by heterogeneity in preferences or beliefs. Can we attribute the observed heterogeneity in contribution dynamics in our data to the composition regarding cooperative/distributive preferences of the players in these super-groups? Table 10 compares cooperative and distributive preferences of members in failed and in other (successful and mixed) super-groups. Indeed, failed super-groups consist of a higher fraction of non-cooperators, i.e. the average unconditional contribution of their members is lower in both Part 1 and Part 3. A higher percentage of players in those three super-groups are classified as free riders (according to the classification criteria in Fischbacher et al., 
2001), and they also fully free-ride on the other two members in the one-shot distribution decision in Part

2. Nevertheless, none of the comparisons is statistically significant. While this could be caused by the limited number of observations, it also suggests that the composition in terms of cooperative and distributive preferences alone cannot fully account for super-group heterogeneity in performance.

\section{Table 10. Average characteristics of failed and other super-groups}

\begin{tabular}{|c|c|c|}
\hline $\begin{array}{l}\text { Characteristics of members within a super- } \\
\text { group }\end{array}$ & $\begin{array}{c}\text { Failed super-groups } \\
(1,2,4)\end{array}$ & $\begin{array}{l}\text { Other super-groups } \\
(3,5,6,7,8)\end{array}$ \\
\hline Part 3 average contributions & 5.52 & 8.14 \\
\hline Part 1 unconditional contributions & 7.37 & $\mathrm{p}=0.15$ \\
\hline Part 1 Percentage of free-riders & $22.22 \%(6 / 27)$ & $\begin{array}{l}p=0.61 \\
p=0.11\end{array}$ \\
\hline $\begin{array}{l}\text { Part } 2 \text { Percentage of type "Exploit both } \\
\text { members" }\end{array}$ & $66.67 \%(18 / 27)$ & $53.33 \%(24 / 45)$ \\
\hline
\end{tabular}

Notes: The tests comparing percentages are two-sided proportional test. Chi-squared test and fisher's exact test yield very similar results.

\section{Conclusion}

This paper examines the effects of electoral delegation in global public good provision, with a focus on the strategic interactions between voters and the elected delegates. Our results suggest that compared to a non-hierarchical situation, electoral delegation significantly increases inter-group cooperation levels. Moreover, the election process effectively prevents voters to be massively exploited by the delegates. Nevertheless, the actual levels of contribution with delegation fall significantly short of the theoretical predictions, even under the assumption of selfish preferences. Interestingly, we observe a decrease in cooperation level over time, in contrast to theoretical predictions based on selfish preferences and on most parameter combinations for inequity-averse preferences. The reason lies in the heterogeneity in cooperative attitudes across groups, combined with a strong motive among voters for equal contributions.

The combination of (i) delegation based on (re)-elections and (ii) heterogeneity in other-regarding preferences leads to an inefficiency that we call $P$-inefficiency, because it is related to the poly-centric nature of the public good provision and management. Both ingredients - delegation based on elections (or more generally: reputational concerns) and heterogeneity across different groups in terms of otherregarding preferences - are obviously necessary for existence of the P-inefficiency. Notice that the level of the inefficiency is not negligible. For our parameters, towards the end of the interaction with 
delegation, it amounts to almost 50\% of the maximal efficiency level implied by the standard solution. Intuitively, group members neither want to be exploited by their delegates nor by other groups in the society. As a consequence, if the levels of contributions across groups are different, we observe a similar, albeit slower, decay of contribution levels as in the standard linear public goods game. With delegation, groups cannot coordinate on the Pareto-optimal outcome, even in a repeated interaction. In other words, social comparison leads to significant under-contribution with regard to most of our theoretical benchmarks. Interestingly, when levels of cooperation decay over time, there does not seem to be an increase in the number of exploitation events in which group members are exploited by their delegates. Rather, contributions levels get stuck on low levels.

On a more general account, we provide another piece of evidence for a setup in which the combination of reputational concerns and other-regarding preferences lead to potential inefficiencies. Angelova et al. (2012) study a completely different setup - a principal agent game with partly incomplete contracts in which the principal employs a short-term agent and a long-term agent alongside each other, where only the latter has reputational concerns - but also observe a similar kind of inefficiency whose existence requires a certain level of other-regarding preferences.

Additionally, the results of our experiment are able to offer insights on the general trade-off regarding the appropriate characteristics of representatives in delegation problems: On the one hand, since no one wants to be exploited by other groups, voters would like to be represented by smart and strategic delegates (leaders). On the other hand, voters face the risk that such an opportunistic delegate (leader) favors herself or small interest groups at the cost of the majority. Such sorts of dilemmas in selecting the best candidate do not only exist in politics, but also in corporations, organizations and communities, where the elected delegate has some discretionary power over the distribution of benefits and costs. More research in a similar spirit seems warranted as a perquisite for better understanding leadership.

The results of this paper imply that the efficiency effects of delegation mechanisms in organizing global public good provision could be problematic. Albeit oversimplified, this conclusion is consistent with the fact that many self-enforcing international environmental agreements (IEA) (such as the Kyoto protocol) seem to fail in improving efficiency substantially over the non-cooperative outcome. Other results suggest that a big obstacle to such international cooperation is the lack of effective enforcement and monitoring power at the global level. The P-inefficiency seems to be an additional obstacle that has been overlooked so far. Future research is needed to explore issues such as supra-national linkages to reduce the strategic uncertainty in delegates' interactions (Sandler, 1998) or the external validity of our results. Statements of head of states like the ones in climate negotiations that explicitly make conditional offers for the level of climate gas emission reductions make us confident that our setup is also relevant for the real world, albeit it is of course stylized. Nonetheless, our experiment offers a micro-foundation, 
based on specific democratic institutions in a hierarchical provision arrangement for public goods, for the trade-off between efficiency and equity that every society faces. 


\section{References}

Andreoni, J. and L. Gee, 2012. Gun for hire: Delegated enforcement and peer punishment in public goods provision, Journal of Public Economics, 96, 1036-1046.

Angelova, V., W. Güth and M. Kocher, 2012. Co-employment of permanently and temporarily employed agents, Labor Economics, 19, 48-58.

Aronsson, T. and O. Johansson-Stenman, 2014. State-variable public goods when relative consumption matters: A dynamic optimal taxation approach, Economica, forthcoming.

Baldassarri, D. and G. Grossman, 2011. Centralized sanctioning and legitimate authority promote cooperation in humans, Proceedings of the National Academy of Sciences, 108, 11023-11027.

Barrett S., 2007. Why to cooperate. The incentive to supply global public goods. Oxford: Oxford University Press.

Bartling, B and U. Fischbacher, 2012. Shifting the blame: On delegation and responsibility, Review of Economic Studies, 79, 67-87.

Bernard, M., A. Dreber, P. Strimling and K. Eriksson, 2013. The subgroup problem: When can binding voting on extractions from a common pool resource overcome the tragedy of the commons? Journal of Economic Behavior and Organization, 91, 122-130.

Blackwell, C. and M. McKee, 2003. Only for my own neighborhood? Preferences and voluntary provision of local and global public goods, Journal of Economic Behavior and Organization, 52, 115-131.

Bolle, F. and C. Vogel, 2011. Power comes with responsibility—or does it? Public Choice, 148,459-470.

Chaudhuri, A., 2011. Sustaining cooperation in laboratory public goods experiments: a selective survey of the literature. Experimental Economics, 14, 47-83.

Chen, Y and X. Li, 2009. Group identity and social preferences. American Economic Review, 99, 431-457.

Conceicao, P., 2003. Assessing the provision status of global public goods. In: Kaul I. et al. (eds.). Providing global public goods: managing globalization. The United Nations Development Programme. Oxford: Oxford University Press.

Fehr, E. and K. Schmidt., 1999. A theory of fairness, competition and cooperation. Quarterly Journal of Economics, 114, 817-868.

Fellner, G. and G. Lünser, 2014. Cooperation in local and global groups, Journal of Economic Behavior and Organization, forthcoming.

Fischbacher, U., 2007. z-Tree: Zurich toolbox for ready-made economic experiments. Experimental Economics, 10, 171-178. 
Fischbacher, U., S. Gächter, 2010. Social preferences, beliefs, and the dynamics of free riding in public goods experiments. American Economic Review, 100, 541-556.

Fischbacher, U., S. Gächter and E. Fehr, 2001. Are people conditionally cooperative? Evidence from a public goods experiment. Economic Letters, 71, 397-404.

Fleiß, J. and S. Palan, 2012. Of coordinators and dictators: a public goods experiment. Working Paper, Karl-Franzens-University Graz.

Froese, R., D. Zeller, K. Kleisner and D. Pauly, 2012, What catch data can tell us about the status of global fisheries. Marine Biology, 159, 1283-1292.

Greiner, B., 2004. An online recruitment system for economic experiment. In Kremer, K., Macho, V. (eds.). Forschung und wissenschaftliches Rechnen 2003. GWDG Bericht 63. Göttingen, 79-93.

Hamman, J., R. Weber and J. Woon, 2011. An experimental investigation of electoral delegation and the provision of public goods. American Journal of Political Science, 55, 737-751.

Kosfeld, M., A. Okada and A. Riedl, 2009. Institution formation in public goods games. American Economic Review, 99, 1335-1355.

Ledyard, J.O. 1995. Public goods: A survey of experimental research. In: Kagel, J.H. and A.E. Roth. (eds.) Handbook of Experimental Economics. Princeton: Princeton University Press, 111-194.

Löschel, A. and D. Rübbelke, 2014. On the voluntary provision of international public goods. Economica, 81, 195-204.

McCormick, R. and R. Tollison, 1981. Politicians, legislation, and the economy: An inquiry into the interest-group theory of government. Boston: M. Nijhoff.

Markussen, T., L. Putterman and J.R. Tyran, 2014. Self-organization for collective action: An experimental study of voting on sanction regimes. Review of Economic Studies, forthcoming.

Oechssler, J., 2013. Finitely repeated games with social preferences, Experimental Economics, 16, 222231.

Ostrom, E., 2010. Beyond markets and states: Polycentric governance of complex economic systems, American Economic Review, 100, 641-672.

Ostrom, E., C.M. Tiebout and R. Warren, 1961. The organization of government in metropolitan areas: A theoretical inquiry, American Political Science Review, 55, 831-42.

Oxoby, R., 2006. Paretian dictators: Constraining choice in a voluntary contribution game, Working Paper, University of Calgary.

Sandler, S., 1998. Global and regional public goods: A prognosis for collective action, Fiscal Studies, 19, $221-247$.

Tan, F. and E. Xiao, 2012. Peer punishment with third-party approval in a social dilemma game, Economics Letters, 117, 589-591. 
Tavoni, A., A. Dannenberg, G. Kallis and A. Löschel, 2011. Inequality, communication, and the avoidance of disastrous climate change in a public goods game, PNAS, 108, 11825-11829. 


\section{Appendix \\ (not for publication; will be made available online)}

\section{A.1. Proof of Hypothesis 1(c): voting}

We prove that in equilibrium everyone has the same probability to be elected as the delegate. Each player A, B, C has six pure strategies: $(1,2,3),(1,3,2), \ldots$, which give points to candidate $(\mathrm{A}, \mathrm{B}, \mathrm{C})$, respectively.

It is straightforward to show that the only weakly undominated strategy for each player is to assign the most favorable rank (in this case 1) to herself. For instance, assume that A chooses $(2,1,3)$ and B and C choose $(3,1,2)$ and $(2,3,1)$, respectively, so that the total ranks are 7,5 , and 6 for the three candidates. In this situation, A loses outright. If A chooses $(1,2,3)$ instead, the total ranks will be 6,6 , and 6 points for the three candidates, a three-way tie in which A has a strictly higher probability of winning. A similar analysis can be applied to other ranking combinations.

Given that players assign the most favorable rank to themselves, the question becomes how they allocate ranks 2 and 3 to the other two candidates. We analyze the following reduced game. The payoffs which are defined as the probability of winning the election and normalized to 1 for convenience are displayed in the order A, B, C. We define choosing a player by "assigning rank 2 to this player and rank 3 to the third player".

A

\begin{tabular}{|c|c|c|}
\hline Pl. B A & $\underline{1}, 0, \underline{0}$ & $0, \underline{1}, \underline{0}$ \\
\hline $\mathrm{C}$ & $\frac{1}{3}, \frac{1}{3}, \frac{1}{3}$ & $\underline{0}, \underline{1}, 0$ \\
\hline
\end{tabular}

B
Pl. C

A $\quad$ B

\begin{tabular}{|c|c|c|}
\hline A & $\underline{1}, \underline{0}, 0$ & $\underline{\frac{1}{3}}, \underline{\frac{1}{3}}, \underline{\frac{1}{3}}$ \\
\hline $\mathrm{C}$ & $0, \underline{0}, \underline{1}$ & $\underline{0}, 0, \underline{1}$ \\
\hline
\end{tabular}

C

Pl. A

Based on the payoff matrix, there are two pure strategy equilibria in this game: $\{A:(1,2,3), B$ : $(3,1,2), \mathrm{C}:(2,3,1)\}$ and $\{\mathrm{A}:(1,3,2), \mathrm{B}:(2,1,3), \mathrm{C}:(3,2,1)\}$.

Now consider mixed strategy equilibria. Define $\mathrm{p}_{i}^{j}$ as the probability that player $i$ chooses player $j$ (assigning rank 2 to player $j$ ). In our game, player A chooses player B if player A's expected payoff 
(probability of winning) is at least as large as for choosing $\mathrm{C}$ (she is indifferent if the expected payoffs are the same):

$$
\mathrm{E}\left[\pi_{\mathrm{A}} \mid \mathrm{B}\right]=\mathrm{p}_{\mathrm{B}}^{\mathrm{A}} \mathrm{p}_{\mathrm{C}}^{\mathrm{A}}+\frac{1}{3}\left(1-\mathrm{p}_{\mathrm{B}}^{\mathrm{A}}\right) \mathrm{p}_{\mathrm{C}}^{\mathrm{A}} \geq \mathrm{p}_{\mathrm{B}}^{\mathrm{A}} \mathrm{p}_{\mathrm{C}}^{\mathrm{A}}+{ }_{3}^{1} \mathrm{p}_{\mathrm{B}}^{\mathrm{A}}\left(1-\mathrm{p}_{\mathrm{C}}^{\mathrm{A}}\right)=\mathrm{E}\left[\pi_{\mathrm{A}} \mid \mathrm{C}\right]
$$

The left- and right-hand sides give A's expected payoffs for choosing B and C, respectively. The parameters $\mathrm{p}_{B}^{A}$ and $\mathrm{p}_{C}^{A}$ give the probabilities that $\mathrm{B}$ and $\mathrm{C}$ choose $\mathrm{A}$. Rearranging yields $\mathrm{p}_{C}^{A} \geq \mathrm{p}_{\mathrm{B}}^{\mathrm{A}}$. The intuition is as follows. If player $\mathrm{A}$ knows that player $\mathrm{B}$ is more likely to choose $\mathrm{C}$ over her, then the best response for player $\mathrm{A}$ is to assign a less favorable rank to player $\mathrm{C}$ (i.e., to choose $\mathrm{B}$ ) in order to counterbalance the chance that $\mathrm{C}$ wins the election.

Since the game is symmetric, player $B$ will mix between choosing $A$ and $C$ only if $p_{C}^{B}=p_{A}^{B}$, while player $C$ will mix between choosing $A$ and $B$ only if $p_{A}^{C}=p_{B}^{C}$. Thus, the mixed strategy equilibria should be $p_{B}^{A}=p_{C}^{A}=p_{C}^{B}=p_{A}^{B}=p_{A}^{C}=p_{B}^{C}=0.5$. Each player is indifferent between choosing the other two members. The mixed-strategy Nash equilibrium payoff for each player is $1 / 3$, implying everyone has the same probability to be elected as the delegate.

\section{A.2 Proof of Hypothesis 2 (a) for Baseline contributions (stage game)}

Part 3 In a three-person linear public goods game, the contributions of all group members must be equal in any equilibrium. Otherwise, the member with the highest contribution is always better-off by reducing her contribution. Now suppose $c_{1}=c_{2}=c_{3}$. For any member $c_{i}$, a unilateral deviation by one point increases her monetary earnings by 0.5 points (1-0.5), but increases her advantageous disutility by $\frac{1}{2} \times$ $2 \beta_{\mathrm{i}}$ within the group. It is straightforward that this group member chooses not to decrease her contribution when $\beta_{\mathrm{i}} \geq 0.5$. Assume that the distribution of $\beta$ parameters among delegates is common knowledge. Under this assumption, only when all members are sufficiently advantageously inequity-averse (i.e., $\beta_{\mathrm{i}} \geq 0.5 \forall i$ ) there exist multiple Pareto-ranked equilibria, each of which implies the same level of weakly positive contributions for all group members, $c_{i}=c \in[0,20]$. If one group member satisfies $\beta_{i}<$ 0.5 , complete free-riding $\left(c_{i}=0 \forall i\right)$ is the unique equilibrium outcome.

\section{Part 4 (Case 1): Three-person reference group}

The analysis in this case is similar to that of Part 3, since the only thing that changes is the marginal per capita return (MPCR) of the public account. For any member $c_{i}$, withdrawing one contribution point increases her monetary earnings by 0.83 points (1-1.5/9), instead of 0.5 points as in Part 3 . At the same 
time, disutility from payoff inequity increases by $\frac{1}{2} \times 2 \beta_{\mathrm{i}}$ if the player completely ignores earnings of outgroup members. Obviously, for contributing to become optimal, the monetary gain should not exceed the disutility from earning more than the other group members. This gives the condition $\beta_{i} \geq 0.83$ that has to be fulfilled for the equal contribution equilibrium $c_{i}=c \in[0,20]$. Otherwise, complete free-riding $\left(c_{i}=0 \forall i\right)$ is the unique equilibrium outcome. A stronger sensitivity from advantageous inequity compared to Part 3 is required in the larger group, because defecting become monetarily more profitable.

\section{Part 4 (Case 2): Nine-person reference group}

A change in the reference group does not alter equilibrium outcome for Baseline, due to the fact that 1) the return of the public good is linear and in proportion of the contributions, and 2) an in-group member is not treated differently from an out-group member. In this case, the disutility increases by $\frac{1}{8} \times 8 \beta_{\mathrm{i}}$ if a member tries to undercut her contribution by one point, which is exactly the same as in Case 1 . Therefore, the equilibrium outcome remains the same: $\mathrm{c}_{\mathrm{i}}=\mathrm{c} \in[0,20]$ if $\forall \beta_{i} \geq 0.83$; otherwise, $\mathrm{c}_{\mathrm{i}}=0$ if $\exists \beta_{i}<0.83$.

\section{A.3 Proof of Hypothesis 2 (b) for Delegation contributions (stage game)}

\section{Part 4 (Case 1): Three-person reference group}

Denote contribution for delegates as $\mathrm{c}_{\mathrm{D}}$, and the contributions of the other two members as $\mathrm{c}_{\mathrm{o}}$. In Delegation, delegates play a three-person public goods game, subject to a utility maximization constraint regarding payoff distributions among three members. Note that in any solution, it is not possible that $\mathrm{c}_{\mathrm{D}}>\mathrm{c}_{\mathrm{o}}$, since the delegate could always be better off by decreasing her own contribution. When $\beta_{D}<$ 0.33 , the equilibrium assignment will be $c_{D}=0$ and $c_{o}=20$ for the other group members. Otherwise, if $\beta_{D} \geq 0.33$, a delegate will assign $\mathrm{c}_{\mathrm{D}}=\mathrm{c}_{\mathrm{o}}=0$ for every member. The intuition behind these equilibria is that, when delegates do not care much about earnings of the other two members, they act selfishly by forcing them to contribute fully. When she sufficiently cares about earnings of her group member (but not about out-group members), the optimal strategy is to always equalize everyone's contribution in the group and free ride on other groups by contributing zero.

Suppose $\beta_{D}<0.33$ for all delegates. The proposition is that $\mathrm{c}_{\mathrm{D}}=0$ and $\mathrm{c}_{\mathrm{o}}=20$ is an equilibrium. In such an equilibrium, a delegate has no incentive to increase her own contribution, since the reduction in her advantageous disutility $\left(\frac{1}{2} \times 2 \beta_{\mathrm{D}}\right)$ is strictly smaller than her monetary gain of 0.83 points $\left(1-\frac{1.5}{9}\right)$. Similarly, she has no incentives to decrease others' contributions, since her gain in utility from decreasing the advantageous position $\left(\frac{1}{2} \times \beta_{\mathrm{D}}\right)$ will be smaller than her monetary loss from doing so $\left(\frac{1}{6}\right)$. 
Suppose $\beta_{D} \geq 0.33$ for all delegates. The proposition is that $\mathrm{c}_{\mathrm{D}}=\mathrm{c}_{\mathrm{o}}=0$ is the unique equilibrium. In this case, a unit increase in a group member's contribution leads to a $\frac{1}{6}$ points increase in the delegate's monetary payoff, which is smaller than the inequity gap of $\frac{1}{2} \times \beta_{\mathrm{D}}$. Hence, it is better to equalize the payoffs between herself and the other group members than not. Note that any other positive contribution is not an equilibrium, since a delegate could increase her utility by assigning zero contributions for every member in her group and free-ride on the other groups (that are not in the utility function by definition).

Now suppose one delegate exhibits $\beta_{D} \geq 0.33$, and the other two $\beta_{D}<0.33$. Then, contribution vectors will be $(0,0,0)$ for the group with the inequity-averse delegate and $(0,20,20)$ for the other two. Since the reference group is the three-person group and public good provision is linear, contributions in other groups neither affect the marginal gain/loss analysis nor how incomes within groups are compared.

\section{Part 4 (Case 2): Nine-person reference group}

When the advantageous inequity parameters of all three delegates are larger or equal to 0.83 , then the contribution vector $\mathrm{c}_{\mathrm{i}}=\mathrm{c}=20$ constitutes an equilibrium. A unilateral unit decrease for a delegate leads to 0.83 points of monetary gain, but $\frac{1}{8} \times 8 \beta_{\mathrm{D}}$ units of utility loss. Since $\beta_{\mathrm{D}} \geq 0.83$, the loss is larger than the gain. However, if there exists a delegate with $\beta_{\mathrm{D}}<0.83$, then the unique equilibrium is that every delegate assigns $c_{D}=0$ for herself and $c_{o}=20$ for the other group members. There is no incentive for any delegate to deviate, since a unit increase in her own contribution decreases her monetary benefit by 0.83 points and also her advantageous utility by $\frac{1}{8} \times 2 \alpha_{D}$. Her utility gain compared to the other members who are forced to contribute fully, on the other hand, is strictly smaller $\left(\frac{1}{8} \times 6 \beta_{D}\right)$. 


\section{B. Tables and graphs}

The delegation mechanism significantly increases public goods provision compared to the baseline. Table B1 outlines the results from random effect regressions. The dependent variable is the proportion of total endowment contributed to the public good in a group in Part 4. In both Baseline and Delegation, a group with higher average contributions in Part 3 is also more likely to contribute more in Part $4\left(\beta_{2}\right)$. Nonetheless, even after controlling for that, the delegation mechanism still brings in higher contributions $\left(\beta_{1}\right)$. This result is robust when controlling for time trend $\left(\beta_{3}\right)$ and the interactions between treatments and time $\left(\beta_{4}\right)$.

\section{Table B1. Random effects regression analysis of group contributions in Part 4}

\begin{tabular}{|c|c|c|c|}
\hline \multicolumn{4}{|c|}{ Dependent variable: contributions at the group level } \\
\hline & Model 1 & Model 2 & Model 3 \\
\hline$\beta_{1}$ : Delegation ( 1 for "treatment Delegation") & $\begin{array}{c}0.387^{* * * *} \\
(0.039)\end{array}$ & $\begin{array}{l}0.379^{\text {**** }} \\
(0.037)\end{array}$ & $\begin{array}{l}0.368^{* * * *} \\
(0.057)\end{array}$ \\
\hline$\beta_{2}$ : Part 3 average contribution in group & & $\begin{array}{l}0.198^{* *} \\
(0.078)\end{array}$ & $\begin{array}{l}0.198^{* *} \\
(0.078)\end{array}$ \\
\hline$\beta_{3}:$ Period & & & $\begin{array}{c}-0.014^{* * *} \\
(0.002)\end{array}$ \\
\hline$\beta_{4}:$ Delegation $\times$ Period & & & $\begin{array}{c}0.001 \\
(0.004)\end{array}$ \\
\hline$\beta_{5}:$ Constant & $\begin{array}{c}0.096^{* * * *} \\
(0.013)\end{array}$ & $\begin{array}{c}0.033 \\
(0.023)\end{array}$ & $\begin{array}{c}0.167^{* * *} \\
(0.033)\end{array}$ \\
\hline $\mathrm{R}^{2}$ overall & 0.424 & 0.449 & 0.506 \\
\hline $\mathrm{N}$ & 756 & 756 & 756 \\
\hline
\end{tabular}




\section{Table B2. Random effects regression analysis of group contributions in Delegation}

\begin{tabular}{lc}
\hline Dependent variable: Average contributions in a group \\
\hline Period & $-0.011^{* * *}$ \\
& $(0.003)$ \\
Part 3 average contribution in a group & $0.292^{* *}$ \\
& $(0.145)$ \\
& \\
Delegate being the high contributor in Part 3 & $0.095^{* *}$ \\
& $(0.037)$ \\
Delegate being the low contributor in Part 3 & 0.002 \\
& $(0.048)$ \\
Constant & $0.435^{* * *}$ \\
& $(0.072)$ \\
\hline $\mathrm{R}^{2}$ overall & 0.167 \\
$\mathrm{~N}$ & 432 \\
Groups & 24 \\
\hline
\end{tabular}

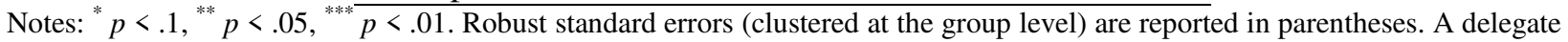
is a "high contributor" if her average contributions in Part 3 is the highest in her group. Likewise, a delegate is a "low contributor" if her contribution in Part 3 is the lowest in her group. 


\section{Table B3. Determinants of election in the first period}

Dependent variable: Whether a subject is elected in the first period (1 means yes)

\begin{tabular}{|c|c|c|c|c|c|}
\hline & (1) & $(2)$ & (3) & $(4)$ & $(5)$ \\
\hline Part 3 rank within group & $-1.218^{* * *}$ & $-1.349^{* * *}$ & $-1.197^{* * *}$ & $-1.164^{* * * *}$ & $-1.238^{* * * *}$ \\
\hline (1 means the high contributor and 3 means the low & $(0.394)$ & $(0.397)$ & $(0.405)$ & $(0.392)$ & $(0.394)$ \\
\hline
\end{tabular}

contributor)

Part 1 free rider

Part 1 hump-shaped/others

Part 2 fully exploit

Part 2 self-serving

Part 3 individual average contribution

\begin{tabular}{|c|c|c|c|c|c|}
\hline Constant & $\begin{array}{l}1.794^{* * *} \\
(0.652)\end{array}$ & $\begin{array}{c}2.347^{* * * *} \\
(0.750) \\
\end{array}$ & $\begin{array}{l}1.804^{* * *} \\
(0.625) \\
\end{array}$ & $\begin{array}{l}1.863^{* * *} \\
(0.660) \\
\end{array}$ & $\begin{array}{l}1.896^{\text {*** }} \\
(0.661)\end{array}$ \\
\hline log-likelihood & -30.89 & -30.26 & -30.71 & -30.24 & -30.87 \\
\hline $\mathrm{N}$ & 72 & 72 & 72 & 69 & 72 \\
\hline
\end{tabular}

$-0.103$

$-0.387$

$(0.867)$

$-0.304$

$-0.096$

$(0.363)$

$-0.008$

$(0.010)$ 
Table B4. Determinants of election in the last election period

Dependent variable: Whether a subject is elected in the last period (1 means yes)

\begin{tabular}{|c|c|c|c|c|}
\hline & $(1)$ & $(2)$ & $(3)$ & $(4)$ \\
\hline Previous delegate & $\begin{array}{c}3.577^{* * * *} \\
(1.332)\end{array}$ & $\begin{array}{c}3.627^{* * * *} \\
(1.371)\end{array}$ & $\begin{array}{l}3.674^{* * *} \\
(1.429)\end{array}$ & $\begin{array}{c}3.783^{* * *} \\
(1.307)\end{array}$ \\
\hline Part 3 rank within group & $\begin{array}{l}-0.129 \\
(0.311)\end{array}$ & $\begin{array}{l}-0.207 \\
(0.350)\end{array}$ & $\begin{array}{c}-0.063 \\
(0.424)\end{array}$ & $\begin{array}{l}-0.040 \\
(0.328)\end{array}$ \\
\hline Previous delegate $\times$ Part 3 rank within group & $\begin{array}{l}-1.209^{* *} \\
(0.605)\end{array}$ & $\begin{array}{l}-1.285^{* *} \\
(0.612)\end{array}$ & $\begin{array}{l}-1.321^{* *} \\
(0.611)\end{array}$ & $\begin{array}{l}-1.309^{* *} \\
(0.572)\end{array}$ \\
\hline Positive deviation & $\begin{array}{c}0.090 \\
(0.163)\end{array}$ & $\begin{array}{c}0.056 \\
(0.154)\end{array}$ & $\begin{array}{c}0.082 \\
(0.189)\end{array}$ & $\begin{array}{c}0.106 \\
(0.181)\end{array}$ \\
\hline $\begin{array}{l}\text { Previous delegate } \times \text { Positive deviations from } \\
\text { super-group averages }\end{array}$ & $\begin{array}{l}-0.857^{*} \\
(0.445)\end{array}$ & $\begin{array}{l}-0.731 \\
(0.467)\end{array}$ & $\begin{array}{l}-0.723 \\
(0.442)\end{array}$ & $\begin{array}{l}-0.881^{* *} \\
(0.443)\end{array}$ \\
\hline Negative deviation & $\begin{array}{c}-0.084 \\
(0.124)\end{array}$ & $\begin{array}{l}-0.086 \\
(0.123)\end{array}$ & $\begin{array}{l}-0.031 \\
(0.128)\end{array}$ & $\begin{array}{c}-0.100 \\
(0.141)\end{array}$ \\
\hline $\begin{array}{l}\text { Previous delegate } \times \text { Negative deviations from } \\
\text { super-group averages }\end{array}$ & $\begin{array}{c}0.288 \\
(0.280)\end{array}$ & $\begin{array}{c}0.258 \\
(0.283)\end{array}$ & $\begin{array}{c}0.473 \\
(0.472)\end{array}$ & $\begin{array}{c}0.268 \\
(0.284)\end{array}$ \\
\hline Part 1 unconditional contribution & & $\begin{array}{l}-0.036 \\
(0.033)\end{array}$ & & \\
\hline Part 1 free rider & & & $\begin{array}{l}1.284^{* *} \\
(0.534)\end{array}$ & \\
\hline Part 2 fully exploit & & & & $\begin{array}{c}-0.046 \\
(0.483)\end{array}$ \\
\hline Part 2 self-serving & & & & $\begin{array}{l}-0.319 \\
(0.561)\end{array}$ \\
\hline Constant & $\begin{array}{l}-0.523 \\
(0.613) \\
\end{array}$ & $\begin{array}{c}-0.073 \\
(0.804) \\
\end{array}$ & $\begin{array}{c}-0.832 \\
(0.804) \\
\end{array}$ & $\begin{array}{l}-0.677 \\
(0.616) \\
\end{array}$ \\
\hline log-likelihood & -35.62 & -34.95 & -29.60 & -33.11 \\
\hline $\mathrm{N}$ & 70 & 70 & 61 & 67 \\
\hline
\end{tabular}


Table B5. Ranking analysis in the first election (ordered logit model)

Dependent variable: voter $i$ 's ranking to candidate $j$ (1-3)

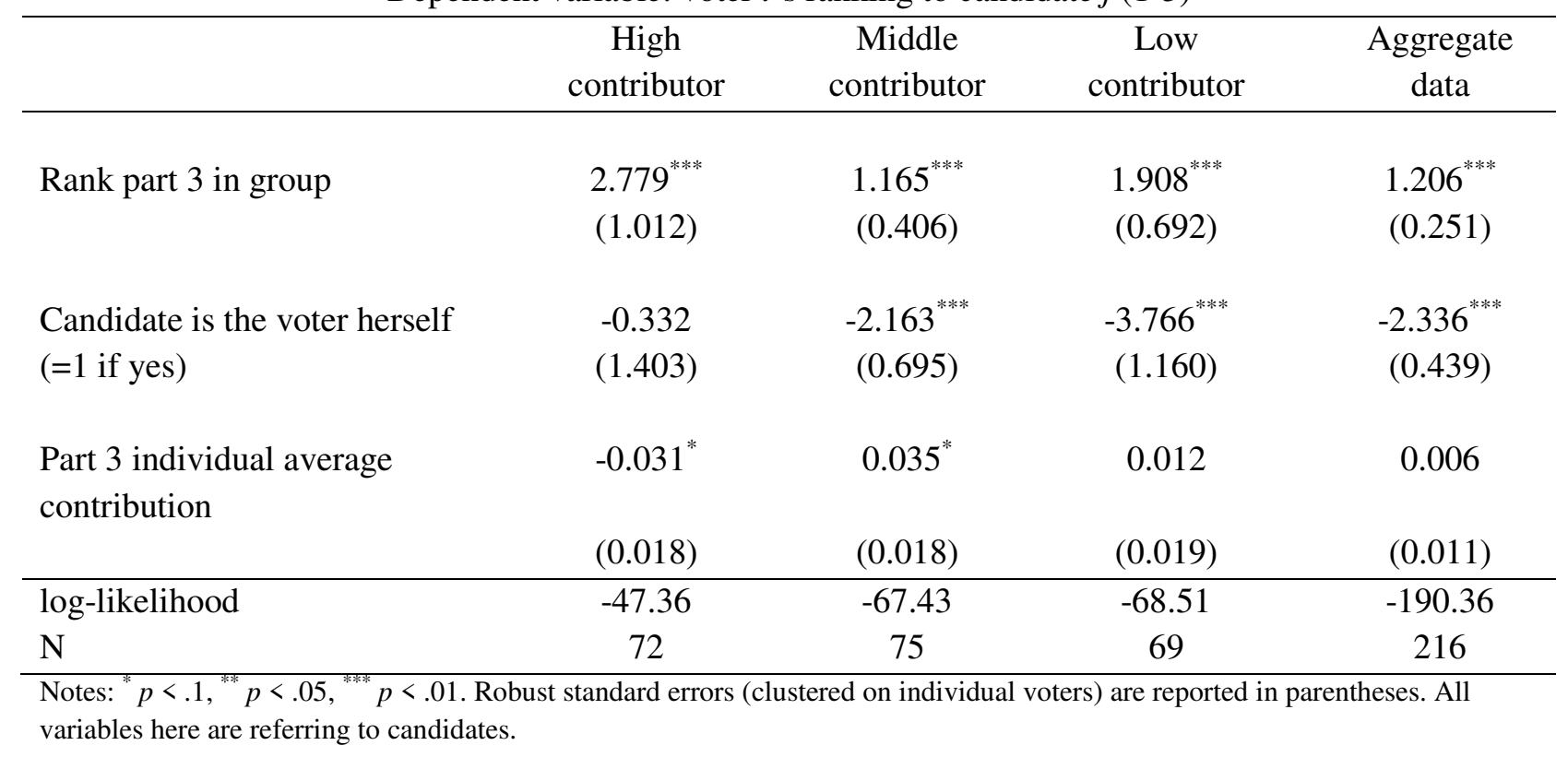


Table B6. Ranking analysis in the last election (ordered logit model)

Dependent variable: voter $i$ 's ranking to candidate $j(1-3)$

\begin{tabular}{|c|c|c|c|c|}
\hline & $\begin{array}{c}\text { High } \\
\text { contributor }\end{array}$ & $\begin{array}{c}\text { Middle } \\
\text { contributor }\end{array}$ & $\begin{array}{l}\text { Low } \\
\text { contributor }\end{array}$ & $\begin{array}{l}\text { Aggregate } \\
\text { data }\end{array}$ \\
\hline Previous delegate & $\begin{array}{c}0.350 \\
(0.712)\end{array}$ & $\begin{array}{l}-1.060 \\
(1.534)\end{array}$ & $\begin{array}{c}1.336 \\
(1.692)\end{array}$ & $\begin{array}{l}-1.609 \\
(1.068)\end{array}$ \\
\hline Rank part 3 in group & $\begin{array}{l}0.828 \\
(0.702)\end{array}$ & $\begin{array}{c}0.507 \\
(0.361)\end{array}$ & $\begin{array}{l}-0.321 \\
(0.696)\end{array}$ & $\begin{array}{c}0.124 \\
(0.208)\end{array}$ \\
\hline Previous delegate $\times$ Rank part 3 in group & a & $\begin{array}{c}0.155 \\
(0.758)\end{array}$ & $\begin{array}{l}-0.968 \\
(0.669)\end{array}$ & $\begin{array}{c}0.675 \\
(0.455)\end{array}$ \\
\hline $\begin{array}{l}\text { Previous delegate } \times \text { Positive deviation from } \\
\text { super-group average }\end{array}$ & $\begin{array}{l}0.938^{* *} \\
(0.468)\end{array}$ & $\begin{array}{c}0.781 \\
(0.589)\end{array}$ & $\begin{array}{l}-1.069^{* *} \\
(0.471)\end{array}$ & $\begin{array}{c}0.408 \\
(0.505)\end{array}$ \\
\hline $\begin{array}{l}\text { Previous delegate } \times \text { Negative deviation from } \\
\text { super-group average }\end{array}$ & $\begin{array}{l}-0.493 \\
(0.347)\end{array}$ & $\begin{array}{l}-0.100 \\
(0.229)\end{array}$ & $\begin{array}{l}-0.523^{* *} \\
(0.221)\end{array}$ & $\begin{array}{l}-0.327^{* *} \\
(0.167)\end{array}$ \\
\hline $\begin{array}{l}\text { Previous delegate } \times \text { Average amount of } \\
\text { exploitation }\end{array}$ & $\begin{array}{c}20.882^{* * *} \\
(0.699)\end{array}$ & $\begin{array}{c}0.110 \\
(0.104)\end{array}$ & $\begin{array}{c}0.094 \\
(0.097)\end{array}$ & $\begin{array}{l}-0.018 \\
(0.085)\end{array}$ \\
\hline Candidate is the voter herself & $\begin{array}{l}-2.506 \\
(1.524)\end{array}$ & $\begin{array}{l}-1.974^{* * *} \\
(0.725)\end{array}$ & $\begin{array}{l}-2.570^{* *} \\
(1.305)\end{array}$ & $\begin{array}{l}-2.552^{* * *} \\
(0.468)\end{array}$ \\
\hline log-likelihood & -57.96 & -70.00 & -58.07 & -197.50 \\
\hline $\mathrm{N}$ & 72 & 75 & 69 & 216 \\
\hline
\end{tabular}


Figure B1. Average earning levels in Part 3 and 4

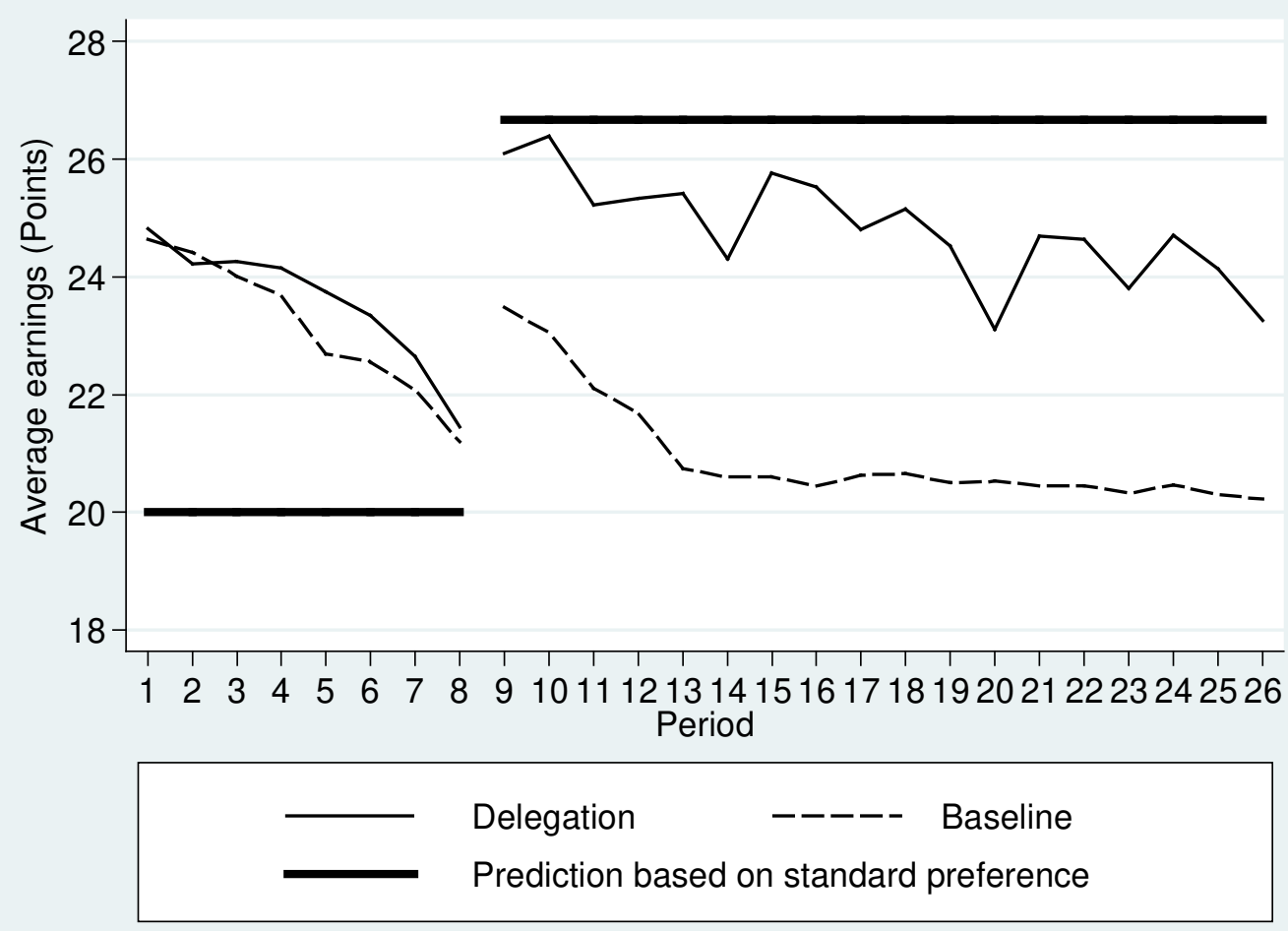




\title{
C. Experiment Instructions (Delegation treatment) Welcome to the experiment and thank you for participating!
}

\author{
Please do not talk to other participants.
}

\begin{abstract}
General
This is an experiment on decision making. You receive $€ 4.00$ for showing up on time. If you read these instructions carefully, you can make good decisions and earn a considerable amount of money that will be paid out to you in cash at the end of the experiment.

The experiment will last approximately two hours. If you have any questions, please raise your hand, and one of the experimenters will come to you and answer your questions privately. During the experiment, your earnings will be calculated in experimental points. At the end of the experiment, all points that you earn will be converted into Euro at the exchange rate announced at the beginning of each part.
\end{abstract}

\section{Anonymity}

You will learn neither during nor after the experiment, with whom you interact(ed) in the experiment. The other participants will neither during nor after the experiment learn, how much you earn(ed). We never link names and data from experiments. At the end of the experiment you will be asked to sign a receipt regarding your earnings which serves only as a proof for our sponsor. The latter does not receive any other data from the experiment.

\section{Means of help}

You will find a pen at your table which we ask that you, please, leave on the table when the experiment is over. While you make your decisions, a clock at the top of your computer screen will run down. This clock will inform you regarding how long we think that the maximum decision time will be. However, if you need more time, you may exceed the limit. The input screens will not be dismissed once time runs out. However, the output/information screens (here you do not have to make any decisions) will be dismissed after time is up.

\section{Experiment}

The experiment consists of four parts. You will receive instructions for each part after the previous part has ended. These instructions will be read to you aloud. Then you will have an opportunity to study them on your own and to ask questions privately.

\section{Part 1}

\section{Exchange rate}

Any point earned in Part 1 will be converted into Euro at the following exchange rate: 10 points = 1 EURO

The basic decision situation

The basic decision situation will be explained to you in the following. Afterwards you will find control questions on the screen that will help you better understand the decision making environment. 
You will be a member of a group consisting of $\mathbf{3}$ members. Each group member has to decide on the allocation of 20 points. You can put these 20 points into your private account or you can put them fully or partially into a group account. Each point you do not put into the group account will automatically remain in your private account.

\section{Your income from the private account:}

You will earn one point for each point you put into your private account. For example, if you put 20 points into your private account (and therefore do not put anything into the group account) your income will amount to exactly 20 points out of your private account. If you put 6 points into your private account, your income from this account will be 6 points. No one except you earns something from your private account.

\section{Your income from the group account:}

Each group member will profit equally from the amount you put into the group account. On the other hand, you will also get a payoff from the other group members' contributions into the group account. The individual income for each group member out of the group account will be determined as follows:

Individual income from group account $=$

Sum of all group members' contributions to the group account $\times 0.5$

If, for example, the sum of all group members' contributions to the group account is 60 points, then you and the other members of your group each earn $60 \times 0.5=30$ points out of the group account. If the three group members contribute a total of 10 points to the group account, you and the other members of your group each earn $10 \times 0.5=5$ points out of the group account.

\section{Total income:}

Your total income is the sum of your income from your private account and that from the group account:

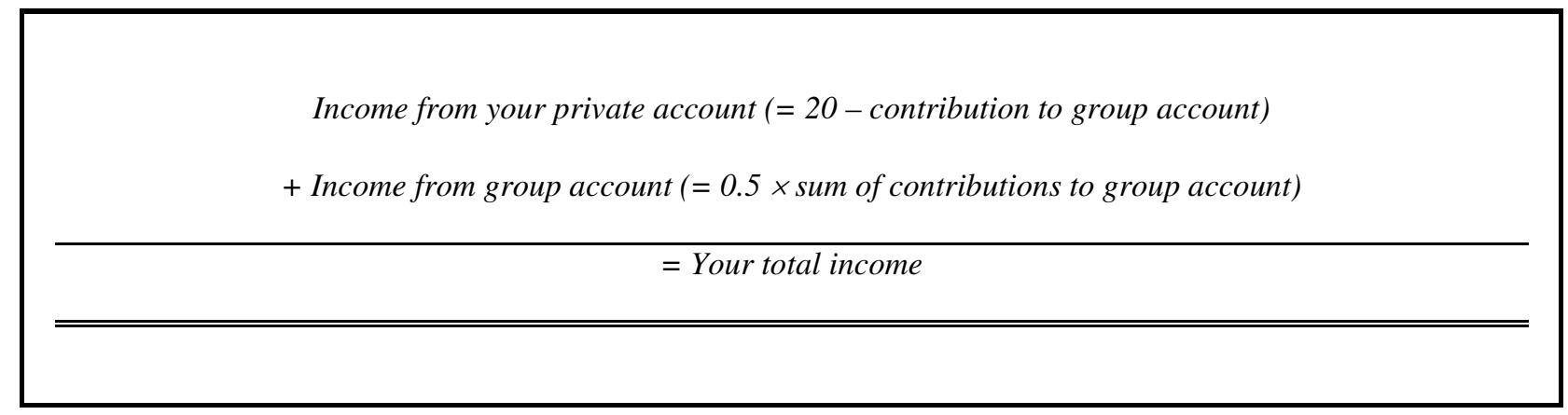

Before we proceed, please try to solve the control questions on your screen. If you want to compute something, you can use the Windows calculator by clicking on the calculation symbol on your screen. 


\section{Procedure of Part 1}

Part 1 includes the decision situation just described to you. The decisions in Part 1 will only be made once.

On the first screen you will be informed about your group membership number. As you know, you will have 20 points at your disposal. You can put them into your private account or you can put them into the group account. Each group member has to make two types of contribution decisions which we will refer to below as the unconditional contribution and the contribution table.

- In the unconditional contribution case, you decide how many of the 20 points you want to put into the group account. Please insert your unconditional contribution in the respective box on your screen. You can insert integers only (e.g., numbers like $0,1,2 \ldots$ ). Your contribution to the private account is determined automatically by the difference between 20 and your contribution to the group account. After you have chosen your unconditional contribution, please click "OK".

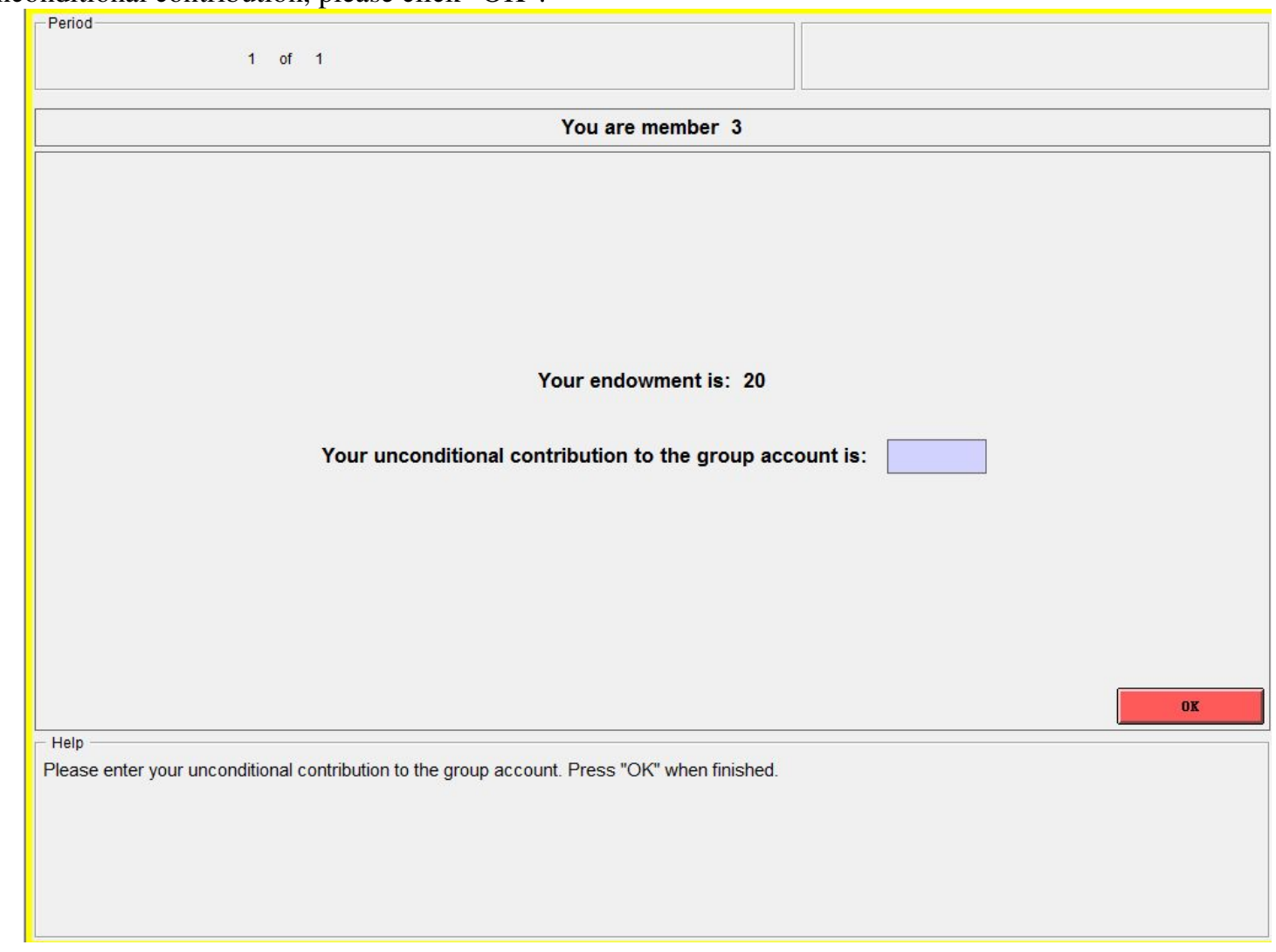


- On the next screen you are asked to fill in a contribution table. In the contribution table you indicate how much you want to contribute to the group account for each possible average contribution of the other group members (rounded up to the next integer). Thus, you can condition your contribution on the other group members' average contributions. The contribution table looks as follows:

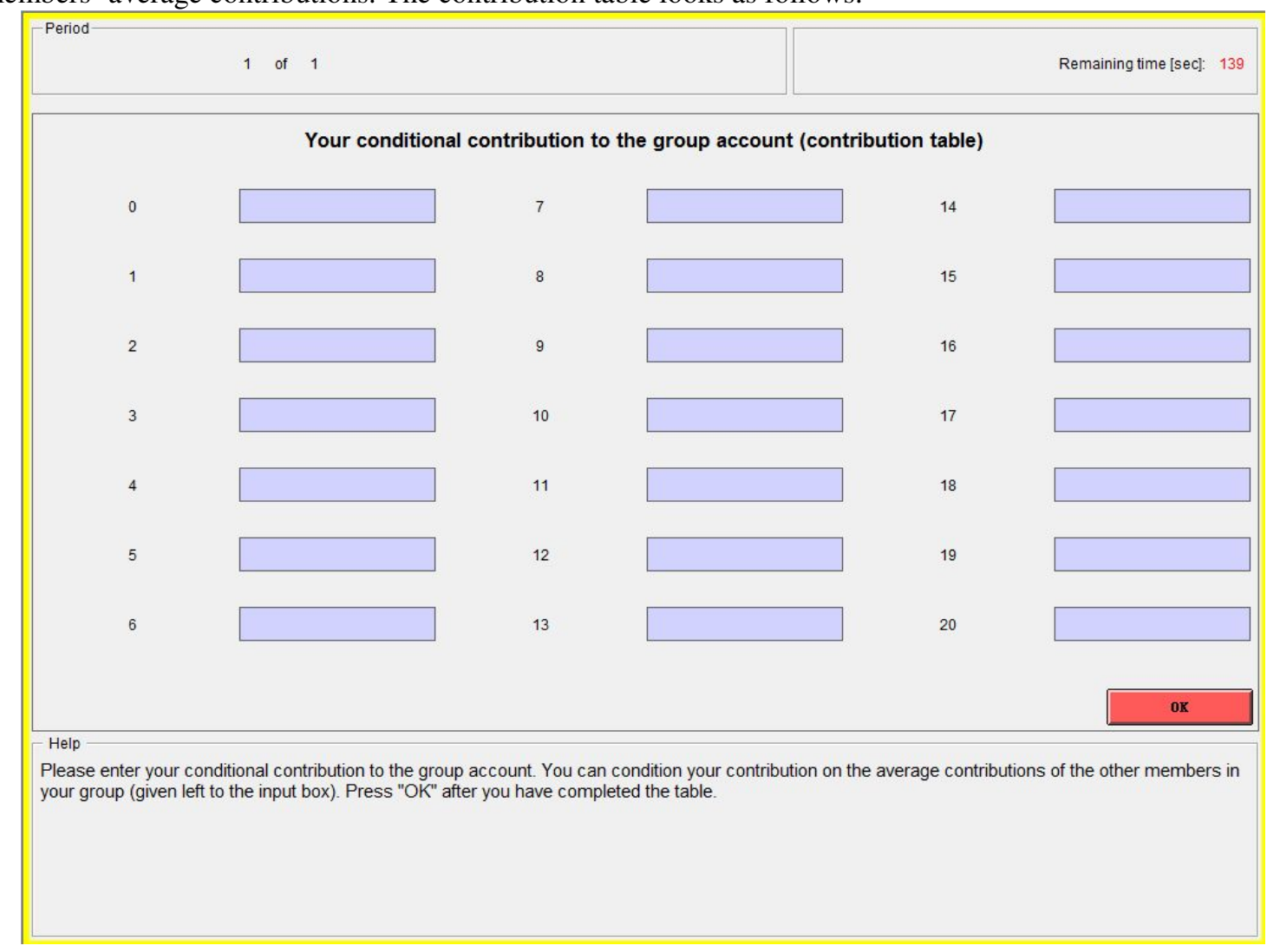

The numbers in each of the left columns are the possible (rounded) average contributions of the other group members to the group account. This means, they represent the average amounts of the other group members' contributions into the group account. You simply have to insert into the input boxes how many points you want to contribute to the group account - conditional on the indicated average contributions. You have to make an entry into each input box. For example, you will have to indicate how much you contribute to the group account if the others contribute 0 point to the group account on average, how much you contribute if the others contribute 1, 2, or 3 points on average, etc. You can insert any whole number from 0 to 20 into each input box. You can of course insert the same number more than once. Once you have made an entry into each input box, please click "OK".

After all participants of the experiment have made their unconditional contributions and have filled in their contribution tables, a random mechanism will select a group member from every group. Only the contribution table will be the payoff-relevant decision for the randomly determined subject. Only the unconditional contribution will be the payoff-relevant decision for the other two group members not selected by the random mechanism. You obviously do not know whether the random mechanism will select you when you make your unconditional contribution and when you fill in the contribution table. You will therefore have to think carefully about both types of decisions because both can become relevant to you. Two examples should make this clear.

Example 1: Assume that the random mechanism selects you. This implies that your relevant decision will be your contribution table. The unconditional contribution is the relevant decision for the other two group members. Assume they made unconditional contributions of 0 and 2 points. The average rounded contribution of these two group members, therefore, is 1 point $((0+2) / 2=1)$. 
- If you indicated in your contribution table that you will contribute 1 point to the group account if the others contribute 1 point on average, then the total contribution to the group account is given by $0+2+1=3$ points. All group members, therefore, earn $0.5 \times 3=1.5$ points out of the group account plus their respective income from the private account. You would then earn in total $(20-1)+1.5=20.5$ points (the sum of your income from your private and the group account).

- If, instead, you indicated in your contribution table that you would contribute 19 points if the others contribute 1 point on average, then the total contribution to the group account is given by $0+2+19=21$ points. All group members therefore earn $0.5 \times 21=10.5$ points out of the group account plus their respective income from the private account. You would then earn in total (20-19) $+10.5=11.5$ points (the sum of your income from your private and the group account).

Example 2: Assume that the random mechanism did not select you, implying that the unconditional contribution is taken as the payoff-relevant decision for you and the other group member. Assume that your unconditional contribution to the group account is 16 points and that of the other group member is 18 points. The average unconditional contribution of you and the other group member, therefore, is 17 points $(=(16+18) / 2)$.

- If the group member whom the random mechanism selected indicates in her contribution table that he/she will contribute 1 point to the group account if the other two group members contribute, on average, 17 points, then the total contribution to the group account is given by $16+18+1=35$ points. All group members will therefore earn $0.5 \times 35=17.5$ points out of the group account plus their respective income from the private account. You would then earn in total $(20-16)+17.5=21.5$ points (the sum of your income from your private and the group account).

- If, instead, the randomly selected group member indicates in her contribution table that he/she will contribute 19 points to the group account if the others contribute, on average, 17 points, then the total contribution to the group account is given by $16+18+19=53$ points. All group members will therefore earn $0.5 \times 53=26.5$ points out of the group account plus their respective income from the private account. You would then earn in total $(20-16)+26.5=30.5$ points (the sum of your income from your private and the group account).

The random selection of the participants will be implemented as follows: The computer will randomly select a number -1, 2 or 3 - after all participants have made their unconditional contributions and have filled in their contribution tables. The randomly selected number will then be compared with the group membership number, which was shown to you on the first screen. If the randomly selected number equals your group membership number, then your contribution table is payoff-relevant for you and the unconditional contribution is payoff-relevant for the other two group members. Otherwise, your unconditional contribution is the relevant decision for you.

You will make all your decisions only once. After the end of Part 1 you will get the instructions for Part 2. How much you have earned in Part 1 will be revealed at the end of the experiment.

\section{Part 2}

\section{Exchange rate}

Any point earned in Part 2 will be converted into Euro at the following exchange rate: 10 points $=1$ EURO

\section{The basic decision situation}

You will be a member of a group consisting of $\mathbf{3}$ members. You are randomly matched anew into a group of 3 at the beginning of this part. Each group member receives a random identification number from 1 to 3 . In Part 1, you were asked to allocate 20 points between your private account and the group account. In this part, you need to decide how to allocate the 20 points for every group member (including yourself) between the two accounts. 
Specifically, for each group member, you need to decide how many points to put into the group account, with the remainder automatically stays in the private account of that group member. You may put in any number of points between and including 0 and 20 points to the group account, and you may select different allocations for each individual.

\section{$\underline{\text { Individual income from Part } 2}$}

The total income of each member is determined in the same way as in Part 1:

Individual income from one's private account ( $=20$ - allocation to group account)

+ Income from group account $(=0.5 \times$ sum of total allocations to group account $)$

$=$ Your total income

Example: Assume that you decide to allocate 12 points to the group account for yourself, 6 points to the group account for the second member and 0 point for the third member. In this case, the group account collects $12+6+0=18$ points. This means that each member in your group receives $18 \times 0.5=9$ points from the group account.

Your total income: $(20-12)+0.5 \times 18=17$ points;

The total income of the second group member: $(20-6)+0.5 \times 18=23$ points;

The total income of the third group member: $(20-0)+0.5 \times 18=29$ points.

After you have made the allocation decisions for all group members, the program will randomly select one member from your group and implement her allocation decisions for payment. Each of the three members in your group is equally likely to be chosen. If you are chosen, your decisions are payoff-relevant for you in Part 2. If another group member is chosen, her or her decisions are payoff-relevant for you in Part 2. How much you have earned in Part 2 will be revealed at the end of the experiment.

The decisions in Part 2 will only be made once. After the end of Part 2 you will get the instructions for Part 3. Before we start you have to answer the control questions.

\section{Part 3}

\section{Exchange rate}

Any point earned in Part 3 will be converted into Euro at the following exchange rate:

\section{0 points $=1$ EURO}

\section{Periods}


The third part of the experiment will last 8 periods. The 8 periods follow exactly the same procedure. You are randomly matched anew into a group of 3 at the beginning of this part. The group composition does not change over the 8 periods. That means your group consists of the same people in all 8 periods. Each group member receives a random identification number from 1 to 3 . This number will remain fixed.

\section{The basic decision situation}

The basic decision situation is the same as the one described in the instructions for the previous parts. In every period, each member of the group has to decide upon the allocation of the 20 points. You can put these 20 points into your private account or you can put them fully or partially into a group account. Each point you do not put into the group account automatically stays in your private account. The only difference to the first part is that you can only provide an unconditional contribution. There is no contribution table in this part. Every member's total income in each period depends on all members' unconditional contribution decisions.

\section{Your income from the private account:}

As in Part 1, you will earn one point for each point you put into your private account. No one except you earns something from your private account.

\section{Your income from the group account:}

The individual income for each group member from the group account will also be determined in the same way as in Part 1:

Individual income from group account $=$

Sum of all group members' contributions to the group account $\times 0.5$

\section{Total income:}

Your total income is determined in the same way as in Part 1:

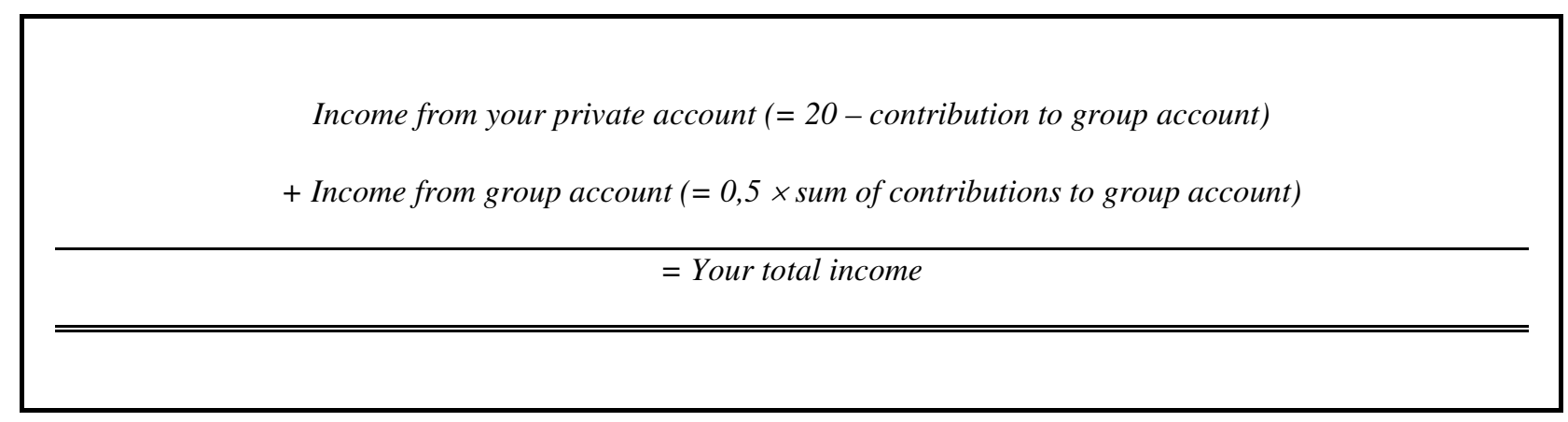

The decision screen, which you will see in every period, looks like this: 


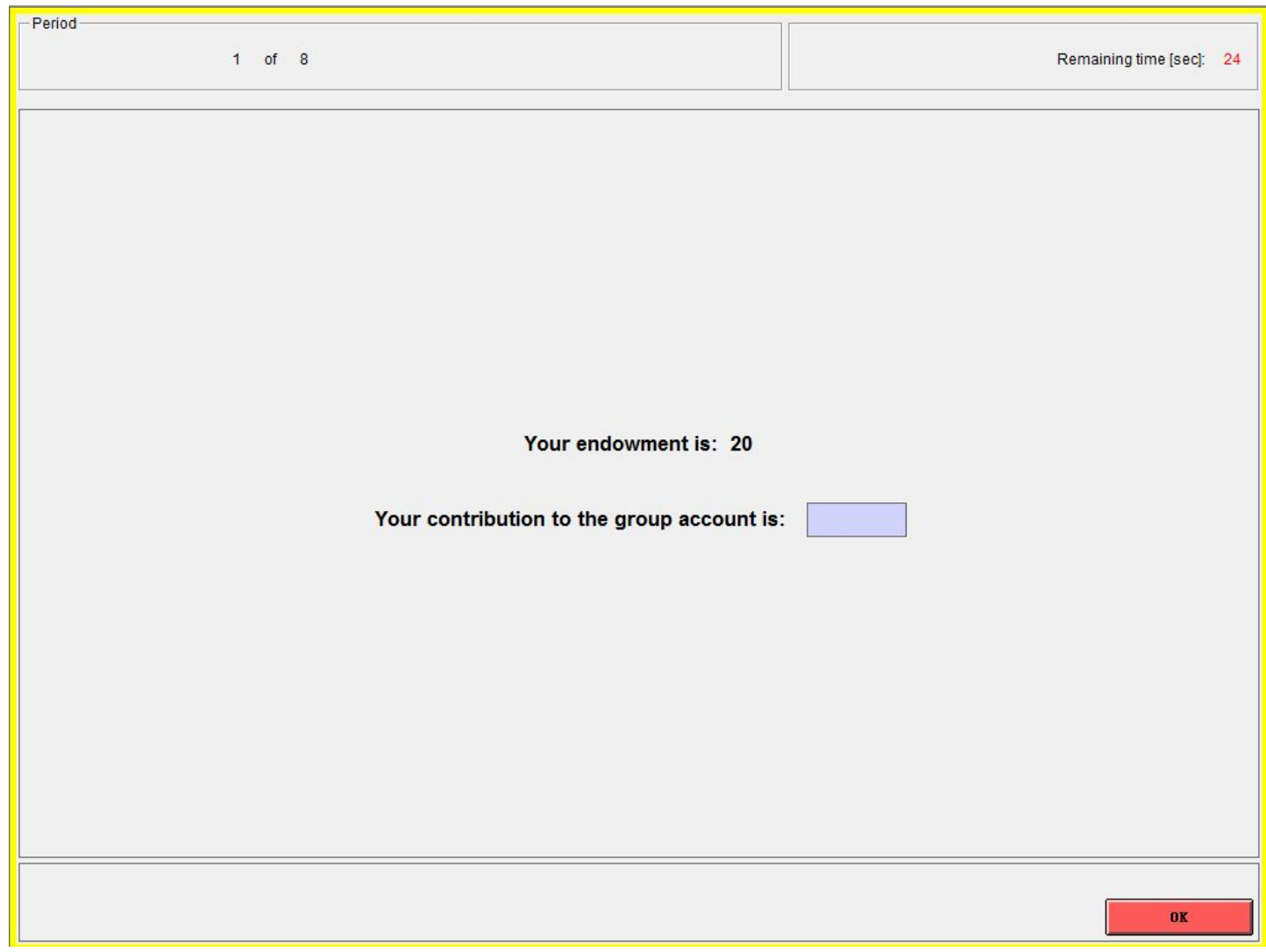

There is no conditional contribution table. You only need to decide on your unconditional contribution in every period. At the end of every period, each experiment participant receives feedback on the results of the period, including the individual contributions of each group member and every member's income from that period.

Your earnings from Part 3 will be the sum of your total income from the 8 periods of Part 3, and it will be paid out in cash to you at the end of the experiment. After the end of Part 3 you will get instructions for Part 4.

\section{Part 4}

\section{Exchange rate}

Any point earned in Part 4 will be converted into Euro at the following exchange rate: 50 points $=\mathbf{1}$ EURO

\section{Periods}

Part 4 consists of 18 periods in which participants remain in the same groups and receive the same identification numbers (ID numbers) as in Part 3.

\section{Super-group}

In Part 4, your group and two other groups will be randomly matched to a super-group of 9 members. You are asked to vote for one member in your group to allocate the 20 points between the private account and the super-group account on your behalf. We will call the elected member allocator. Your earnings in this part will be determined by 
the decisions of the allocator selected from your group as well as the decisions of the allocators from the other two groups. The following sections describe the election, allocation and payoff calculation in turn.

\section{Election}

Election will take place at the beginning of every third period. During the election stage, you will see the average contributions of all three members in your group from Part 3 of the experiment and all decisions from the previous three periods of Part 4 (in the first vote, you only see the average contributions from Part 3). During the election, you can express your preferences for the allocator in your group. In particular, you are asked to rank the three members in your group (including yourself). The highest or most favorable rank is "1", and your least favorable rank is " 3 ". Ties are not allowed - that is, you cannot give the same rank to more than one candidate.

After every group member has completed their rankings, the computer will sum up the ranks of all candidates. The member who has the lowest sum of ranks will be the allocator of her group in the following three periods. In case of ties, one person will be randomly selected (with equal probability) from those who received the lowest ranks.

After the election, you will see the ID number of the allocator. You will not see the total ranks for each member. The tenure of an allocator ends after three periods, and there will be a new election at the beginning of the fourth period, the seventh period, the tenth period, the thirteenth period and the sixteenth period. The same allocator can be elected more than once.

\section{Allocation}

The allocator will decide how to allocate the points of her or her own-group members' between their private accounts and the super-group account in each of the three periods. Hence, there are three allocation decisions. Specifically, for each own group member, the allocator will decide how many points to put into the super-group account, with the remainder automatically stays in that member's private account. The allocator may assign any whole number of points between and including 0 and 20 to allocate to the super-group account for each member in the group (including him- or herself). The allocator may select different allocations for each individual.

\section{Payoff calculation}

Similar to Part 3, your final income is the sum of your income from your private account and the return from the super-group account. The super-group account collects the sum of all contributions of the 9 super-group members (where the decisions on the individual contributions to the super-group account are taken by the three allocators). Define $c_{\mathbb{N}}^{K}$ as the contribution of member $\mathrm{N}$ in group $\mathrm{K}$ determined by the allocator of group $\mathrm{K}$. The sum of contributions to the super-group account is then:

$$
C=C_{1}^{1}+C_{2}^{1}+C_{3}^{1}+C_{1}^{2}+C_{2}^{2}+C_{3}^{2}+C_{1}^{3}+C_{2}^{3}+C_{3}^{3} .
$$

The three $C_{N}^{1}$ are determined by the allocator of group 1 , the three $\mathrm{C}_{\mathrm{N}}^{2}$ are determined by the allocator of group 2 , and the three $\mathrm{C}_{\mathrm{N}}^{3}$ are determined by the allocator of group 3. The amount $\mathrm{C}$ is multiplied by 1.5 and the resulting amount of $1.5 \times \mathrm{C}$ is distributed equally to the three groups. Each group thus receives $0.5 \times \mathrm{C}$. Within the group, the amount is also divided equally: Each member thus receives $(0.5 \times \mathrm{C}) / 3$.

The following examples illustrate how your income is calculated.

Example 1: Assume that the allocator of your group decides to allocate 14 points to the super-group account for you, 6 points to the super-group account for the other group member and 0 point to the super-group account for himor herself. In this case, the total contribution of your group to the super-group account is 20 points. Now further assume that the total contributions of the other two groups are 40 and 60 points. In that case, the total contribution to 
the super-group account will be $20+40+60=120$ points. Your group as a whole (and each other group) gets $0.5 \times 120=60$ points as return from the super-group account. Then the 60 points are equally shared by the three group members. This means each member in your group receives $60 / 3=20$ points from the super-group account.

Your total income: $20-14+(0.5 \times(20+40+60)) / 3=26$ points;

The total income of the other group member: $20-6+(0.5 \times(20+40+60)) / 3=34$ points;

The total income of the allocator: $20-0+(0.5 \times(20+40+60)) / 3=40$ points.

Example 2: Assume that the allocator of your group decides to allocate 5 points to the super-group account for you, 10 points to the super-group account for the other group member and 15 point to the super-group account for him- or herself. In this case, the total contribution of your group to the super-group account is 30 points. Now further assume that the total contributions of the other two groups are 0 and 60 points. In that case, the total contribution to the super-group account will be $0+30+60=90$ points. Your group as a whole (and each other group) gets $0.5 \times 90=45$ points as return from the super-group account. Then the 45 points are equally shared by the three group members. This means each member in your group receives $45 / 3=15$ points from the super-group account.

Your total income: $20-5+(0.5 \times(0+30+60)) / 3=30$ points;

The total income of the other group member: $20-10+(0.5 \times(0+30+60)) / 3=25$ points;

The total income of the allocator: $20-15+(0.5 \times(0+30+60)) / 3=20$ points.

Example 3: Assume that the allocator of your group decides to allocate 20 points to the super-group account for every group member. Now suppose that the total contributions of the other two groups are both 0 points. In that case, the total contribution to the super-group account will be $60+0+0=60$ points. Your group as a whole (and each other group) gets $0.5 \times 60=30$ points as return from the super-group account. Then the 30 points are equally shared by three group members. This means each member in your group receives $30 / 3=10$ points from the super-group account.

Since the allocator of your group lets every member contribute the same to the super-group account, the total income of every member is: $(20-20)+(0.5 \times(60+0+0)) / 3=10$ points.

The purpose of the above examples is to clarify the payoff calculations, rather than to provide advice on how to act. You should make decisions as you wish.

\section{Feedback}

At the end of every period, every member will receive an information screen regarding the ID number of the allocator, the allocated contribution and income of every member, and the total contributions of each of the three groups.

Your earnings from Part 4 will be the sum of your total income from the 18 periods of Part 4 . After the 18 periods, you will be asked to complete a short questionnaire. This will conclude the experiment. You will receive information on your income for Parts 1 and 2, and we will pay you your earnings in private. 